\title{
The role of elastases in pancreatic diseases
}

\author{
Ph.D. Thesis
}

Anna Zsófia Tóth M.D.

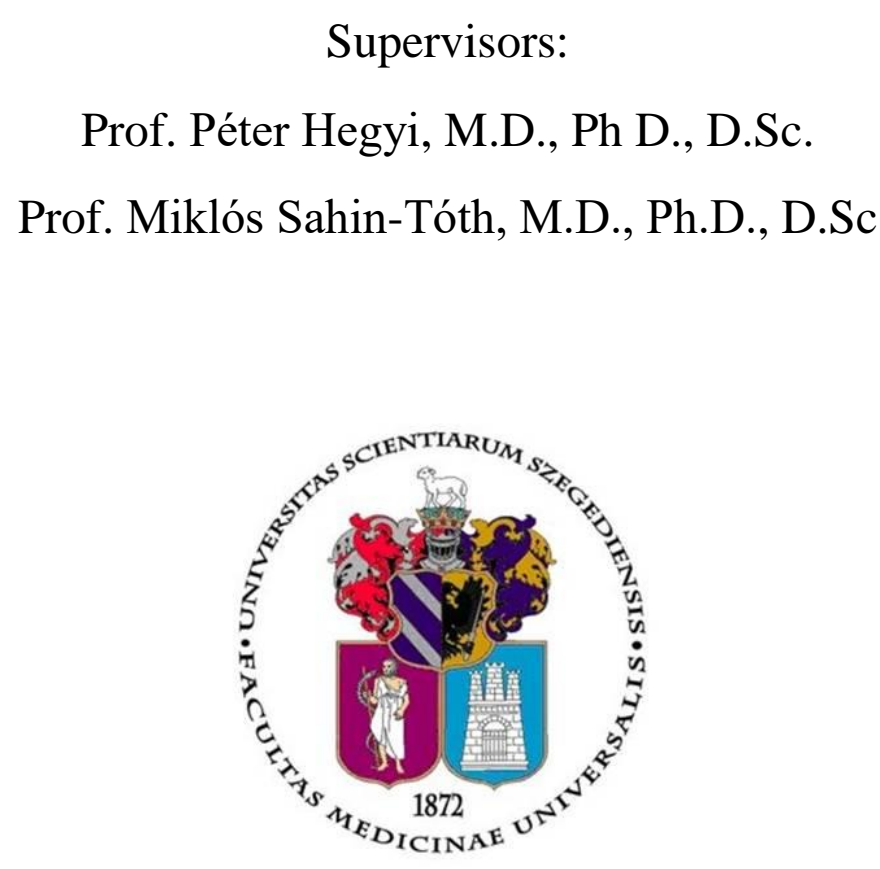

Doctoral School of Theoretical Medicine

Szeged

2018. 


\section{Content}

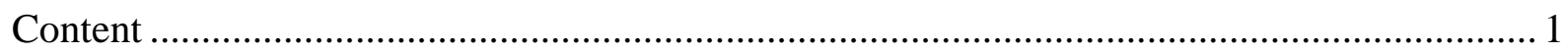

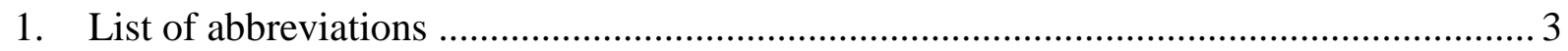

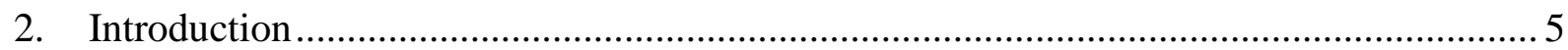

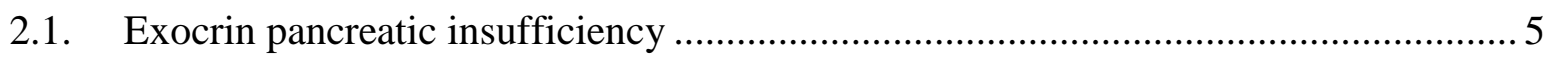

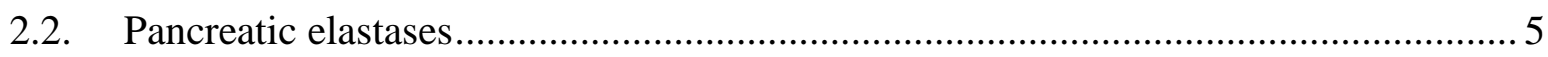

2.3. Pancreatic function tests based on detection of elastases ......................................... 7

2.4. Possible role of elastases in chronic pancreatitis ..................................................... 8

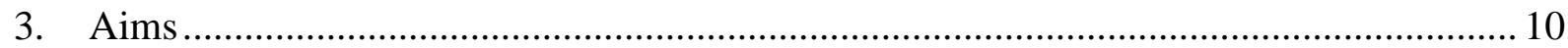

3.1. ScheBo Pancreatic Elastase 1 Test Study ............................................................ 10

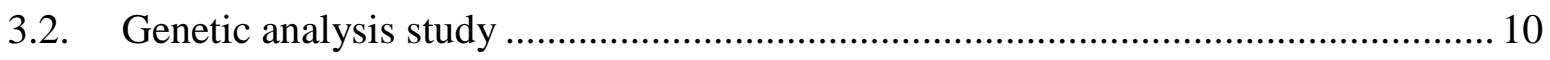

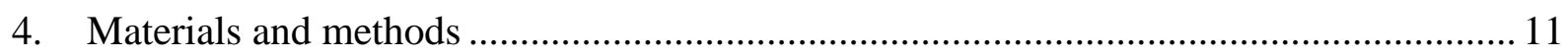

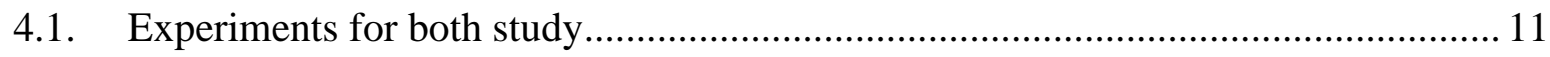

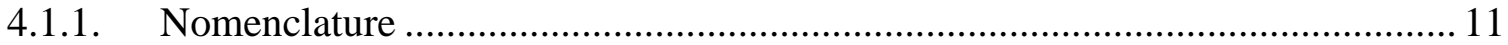

4.1.2. Plasmid construction and mutagenesis ........................................................... 11

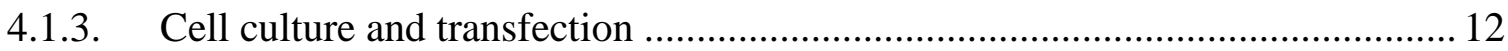

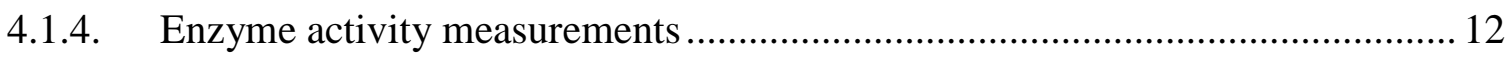

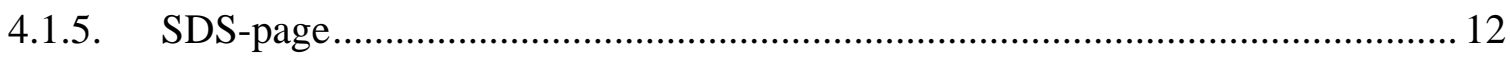

4.1.6. Purification of pancreatic proteinases ............................................................ 13

4.1.7. Expression and purification of autolyzed CELA3B forms …………………..... 13

4.2. Experiments with the ScheBo Pancreatic Elastase 1 test .......................................... 14

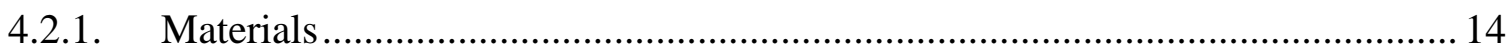

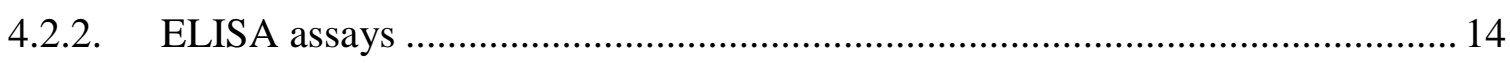

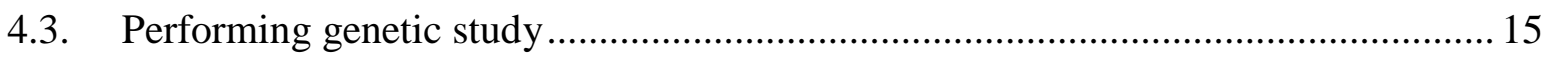

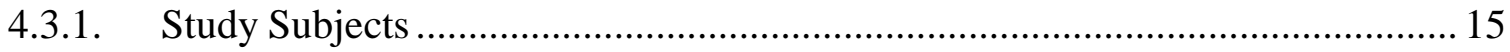

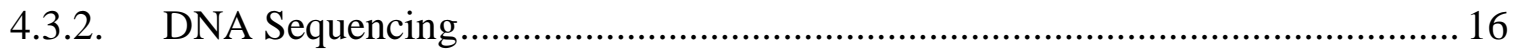

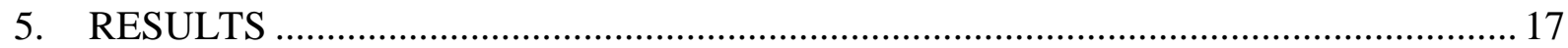

5.1. ScheBo Pancreatic Elastase 1 Test results................................................................. 17

5.1.1. The ScheBo Pancreatic Elastase 1 Stool Test detects elastase 3 isoforms CELA3A and CELA3B 17 
5.1.2. Proelastases, active elastases and autolyzed elastase forms are measured with

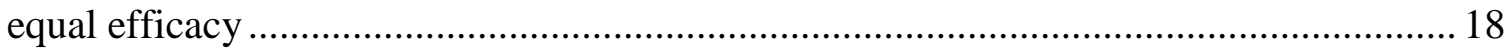

5.1.3. Effect of CELA3A and CELA3B genetic variants on the performance of the

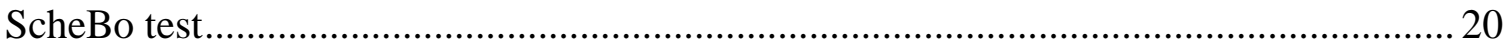

5.1.4. Glu154 in CELA3B is a critical determinant of recognition by the ScheBo test 21

5.1.5. Mutations of Lys154 and nearby Arg179 improve detection of CELA3A ........ 25

5.1.6. DNA Sequence Analysis of Exon 7 of Human CELA3A and CELA3B ........... 26

5.1.7. Functional Analysis of Missense Variants and the Gene Conversion Event ..... 32

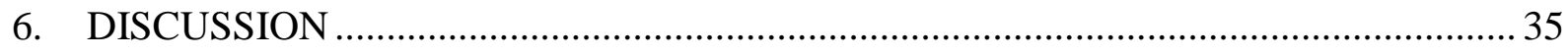

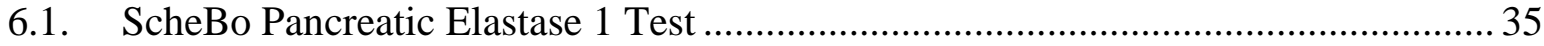

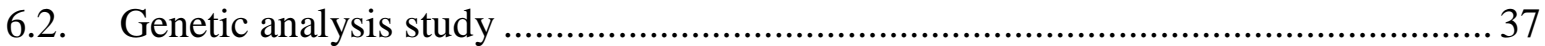

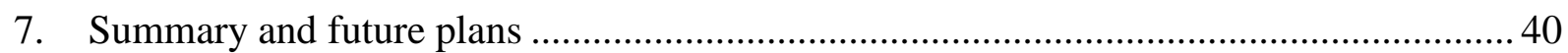

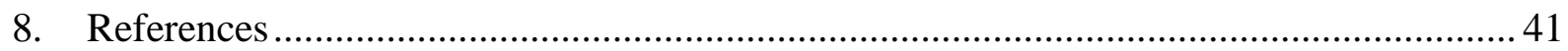

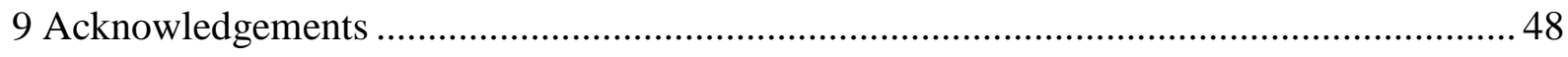

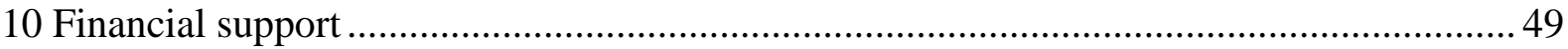




\section{List of abbreviations}

A: adenin

ACP: alcoholic chronic pancreatitis

C: citosine

CELA: chymotripsin-like elastase

CFTR: cystic fibrosis transmembrane conductance regulator

CI: confidental interval

CO2: carbon dioxide

CP: chronic pancreatitis

CPA1: carboxypeptidase A1

CTRB: chymotrypsin B

CT: computer tomography

CTRC: chymotrypsin

CTRL1: chymotrypsin-like protease

DNA: deoxyribonucleic acid

DMEM: Dulbecco's Modified Eagle's Medium

ELISA: enzyme-linked immunosorbent assay

ERCP: endoscopic retrograde cholangiopancreatography

$\mathrm{G}$ : guanin

$\mathrm{HCl}$ : hydrochloric acid

ICP: idiopathic chronic pancreatitis

MRCP: magnetic resonance cholangiopancreatography

min: minute

NHLBI: National Heart, Lung, and Blood Institute (USA)

OR: odd radio

PCR: polymerase chain reactions

PNGase f: Peptide:N-glycosidase F

PRSS1: protease serine 1, human cationic trypsinogen

SPINK: serine protease inhibitor Kazal type 1

SDS: sodium dodecyl sulfate

T: timin

UV: ultraviolet

9 His: 9 histidine 


\section{Publications related to the subject of the thesis:}

Detection of human elastase isoforms by the ScheBo Pancreatic Elastase 1 test

Tóth Anna Zsófia, Szabó András, Hegyi Eszter, Hegyi Péter, Sahin-Tóth Miklós

American Journal of Physiology-Gastrointestinal and Liver Physiology 2017. March IF:3,4

Genetic Analysis of Human Chymotrypsin-Like Elastases 3A and 3B (CELA3A and CELA3B) to Assess the Role of Complex Formation between Proelastases and Procarboxypeptidases in Chronic Pancreatitis.

Párniczky Andrea, Hegyi Eszter, Tóth Anna Zsófia, Szücs Ákos, Szentesi Andrea, Vincze Áron, Izbéki Ferenc, Németh Balázs Csaba, Hegyi Péter, Sahin-Tóth Miklós

International Journal of Molecular Sciensis. 2016. December IF: 3,2

\section{Publications closely related to the subject of the thesis:}

Pain in the Early Phase of Pediatric Pancreatitis (PINEAPPLE Trial): Pre-Study Protocol of a Multinational Prospective Clinical Trial.

Zsoldos Fanni, Párniczky Andrea, Mosztbacher Dóra, Tóth Anna Zsófia, Lásztity Natália, Hegyi Péter; Hungarian Pancreatic Study Group and the International Association of Pancreatology.

Digestion. 2016. December IF: 2,088

Analysis of Pediatric Pancreatitis (APPLE Trial): Pre-Study Protocol of a Multinational Prospective Clinical Trial.

Párniczky Andrea, Mosztbacher Dóra, Zsoldos Fanni, Tóth Anna Zsófia, Lásztity Natália, Hegyi Péter; Hungarian Pancreatic Study Group and the International Association of Pancreatology.

Digestion. 2016 November IF: $\mathbf{2 , 0 8 8}$

Number of full publications: 4 (first author: 1)

Cumulative impact factor: 10,76 


\section{Introduction}

\subsection{Exocrin pancreatic insufficiency}

Diseases of the pancreas that result in loss of functional acinar cells can compromise digestive enzyme production and eventually lead to maldigestion. The main etiologic factors of exocrine pancreatic insufficiency in adults are chronic pancreatitis, pancreatic cancer and resection of pancreas. It can also occur in progression of cystic fibrosis especially in infancy and childhood; in conditions with several protein-energy malnutrition or after a total/subtotal gastric resection. Other rare diseases which can lead to exocrine pancreatic insufficiency are Shwachmann-Diamond syndrome, Johanson-Blizzard syndrome, or congenital enzyme insufficiencies such as congenital insufficiency of trypsinogen-, enteropeptidase-, alpha-1 antitrypsine-, amilase-, and lipase. The principal symptoms of pancreatic insufficiency are abdominal pain, bloating, cramping, increased flatulence, diarrhea, steatorrhea and malnutrition. The functional reserve capacity of the exocrine human pancreas is high. According to this observance the main symptoms of exocrine pancreatic insufficiency generally appear at the late stage of the pancreatic diseases, for example steatorrhea does not occur until approximately 90 percent of glandular function has been lost. Impaired enzyme secretion may be complicated by latent fat-soluble vitamin deficiencies. The low level of D3 vitamin increases the incidence of osteoporosis and the risk of fractures. Impaired night vision have been observed in patients with chronic pancreatitis because of the lack of vitamin A. Pancreatic exocrine insufficiency may cause vitamin B12 deficiency because a decreased intestinal $\mathrm{pH}$ adversely affects the transfer of vitamin $\mathrm{B} 12$ from $\mathrm{R}$ protein to intrinsic factor.

Clinical laboratory tests that quantify decreased digestive enzyme output can aid in the diagnosis of pancreatic insufficiency. The most widely used tests measure levels of the pancreatic elastase enzyme in the stool. (Amann, Bishop, Curington, \& Toskes, 1996; Domínguez-Muñoz, D. Hardt, Lerch, \& Löhr, 2017; Dominici \& Franzini, 2002; Hahn et al., 2005; Hardt et al., 2003; Keim, Teich, \& Moessner, 2003; Leeds, Oppong, \& Sanders, 2011; Loser, Mollgaard, \& Folsch, 1996; Lüth et al., 2001; Miendje et al., 2004; Schneider, Funk, Caspary, \& Stein, 2005; Stein et al., 1996; Weiss, Budde, \& Lerch, 2016).

\subsection{Pancreatic elastases}

The chymotrypsin-like elastases (CELAs) are digestive serine proteinases secreted by the pancreas in multiple isoforms. CELA1 was first described by Hungarian scientists Baló and 
Banga (1949) as an enzyme activity in the pig pancreas capable of hydrolyzing insoluble elastin (Baló \& Banga, 1949, 1950). Due to its cationic character, CELA1 can absorb to the surface of the negatively charged elastin fibers and cleave multiple Ala-Ala and Ala-Gly peptide bonds (Gertler, 1971; Gertler, Weiss, \& Burstein, 1977). Despite its name, CELA1 is not a specific elastin-degrading enzyme and it readily digests a variety of dietary protein substrates. The primary specificity pocket of CELA1 accommodates small (Ala, Ser) and aliphatic (Ile, Leu, Met, Val) amino-acid side-chains at the so-called P1 position of its substrates. Schechter-Berger nomenclature (Schechter \& Berger, 2012) of proteinasesubstrate interactions, where P1-P1' corresponds to the scissile peptide bond (Boros et al., 2017). Curiously, while the human CELA1 gene appears to be potentially functional, it is not expressed in the pancreas due to evolutionary mutations in its promoter and enhancer regions (Rose \& MacDonald, 1997; Tani, Kawashima, Furukawa, Ohmine, \& Takiguchi, 1987).

A second pancreatic elastase (CELA2) was identified based on its ability to solubilize elastin (Largman, Brodrick, \& Geokas, 1976). Unlike CELA1, this elastase exhibits chymotrypsinlike P1 specificity and prefers to cleave after aromatic (Tyr, Phe) and aliphatic (Leu, Met) P1 amino-acids (Boros et al., 2017; Largman et al., 1976; Szabó \& Sahin-Tóth, 2012). In humans evolutionary duplication of CELA2 gave rise to the CELA2A and CELA2B genes. Even though both genes are expressed at the mRNA level (Kawashima, Tani, Shimoda, \& Takiguchi, 1987), only the CELA2A enzyme is functional as CELA2B seems to have accumulated inactivating evolutionary mutations (Szepessy \& Sahin-Tóth, 2006). The CELA2A content of pancreatic juice corresponds to about $10 \%$ of total protein (Ohlsson \& Olsson, 1976).

Arguably, CELA3 has the most interesting history and characteristics among the human elastases. This elastase gene is also duplicated in humans and the two closely related isoforms were designated as CELA3A and CELA3B (Shirasu et al., 1988; Tani, Ohsumi, Mita, \& Takiguchi, 1988). Both are expressed in the pancreas at comparable mRNA and protein levels (Shirasu et al., 1988; Tani et al., 1988). Substrate specificity of human CELA3A and CELA3B appear to be similar to that of porcine CELA1, broadly directed toward aliphatic P1 side chains(Boros et al., 2017). CELA3B was first described in 1975 as protease E, an anionic pancreatic proteinase devoid of elastolytic activity (Mallory \& Travis, 1975). A subsequent study in 1976 isolated human CELA3B and CELA2A and designated these enzymes as elastase 1 and elastase 2, respectively (Largman et al., 1976). For reasons that remain unclear, 
the authors found that CELA3B was capable of solubilizing elastin; an erroneous observation which at the time justified the elastase 1 name. Finally, in a number of studies starting in 1982, Sziegoleit and coworkers characterized a so-called cholesterol-binding protein with proteolytic activity, which eventually turned out to correspond to CELA3B (A Sziegoleit, 1982; Andreas Sziegoleit, 1984; Andreas Sziegoleit, Krause, Klör, Kanacher, \& Linder, 1989). These authors also determined that the CELA3B content of human pancreatic juice accounts for 4-6\% of total protein(Andreas Sziegoleit, 1984). Thus, the combined levels of CELA3A and CELA3B are similar to those of CELA2A. Spurred by the observation that CELA3B suffers no proteolytic degradation during intestinal transit and appears in the stool in high concentrations (Andreas Sziegoleit, 1984). ELISA tests have been developed for the detection of stool elastase and their clinical utility in the diagnosis of pancreatic insufficiency has been demonstrated (Domínguez-Muñoz et al., 2017; Hahn et al., 2005; Keim et al., 2003; Leeds et al., 2011; Loser et al., 1996; Lüth et al., 2001; Miendje et al., 2004; Schneider et al., 2005; Stein et al., 1996).

\subsection{Pancreatic function tests based on detection of elastases}

Among non-invasive pancreatic function tests the determination of fecal elastases by ELISA method is a non-invasive, simple, practical and reliable clinical test. The first sandwich-type ELISA for detecting human pancreatic elastases was developed by Sziegoleit et al. in 1989. The test used microtiter plates coated with monoclonal antibodies from sheep against human pancreatic elastases. After incubation with the sample containing elastase and after a washing procedure, plates were incubated with other human pancreas specific antibodies from rabbits. This procedure was followed by the detection by anti-rabbit Ig, streptavidin-biotinylated horseradish peroxidase complex.

Nowadays there are two commercially available pancreatic elastase tests: Schebo Pancreatic Elastase-1 test - based on monoclonal ELISA technique and the BioServ Diagnostics Elastase-1 test - based on polyclonal ELISA technique. According to previous studies both assays are fundamentally equivalent in their ability to classify patients as normal, or as moderately or severely pancreatic insufficient. A recent study characterized the isoform specificity of the BioServ test and found that CELA3A is a target while CELA2A is not detected, however, other pancreatic proteinases were not evaluated in a comprehensive manner (Weiss et al., 2016). 
One of the most widely used assays is the Pancreatic Elastase 1 Stool Test by ScheBo Biotech AG (Giessen, Germany), which utilizes two monoclonal antibodies raised against CELA3B to measure enzyme levels. However, it remains unclear whether the test also detects other elastases, CELA3A in particular, and to what extent the homologous pancreatic trypsins and chymotrypsins might interfere with the assay. More importantly, the potential confounding effect of natural CELA3 variants on test performance has never been evaluated.

\subsection{Possible role of elastases in chronic pancreatitis}

As it mentioned above one of the main etiologic factor of exocrine pancreatic insufficiency is chronic pancreatitis. Chronic pancreatitis (CP) is a progressive, relapsing inflammatory disorder of the pancreas which can develops in the background of genetic susceptibility (J.-M. Chen \& Ferec, 2009; Heiko Witt, Apte, Keim, \& Wilson, 2007; Yadav \& Lowenfels, 2013). Among mutations in the best characterized risk genes PRSS1 (cationic trypsinogen), SPINK1 (pancreatic secretory trypsin inhibitor), and CTRC (chymotrypsin C) which stimulate the activation of trypsinogen resulting elevated trypsin activity in the pancreas (Nemeth \& Sahin-Toth, 2014; Pfutzer et al., 2000; Rosendahl et al., 2008; Szabó \& Sahin-Tóth, 2012; Whitcomb et al., 1996; H Witt et al., 2000), the loss-of-function variants in the CPA1 gene encoding carboxypeptidase A1 were shown to increase risk for early onset CP (Heiko Witt et al., 2013). The majority of impaired CPA1 variants exhibited a secretion defect due to intracellular misfolding and retention. The mechanism of action of CPA1 variants was unrelated to trypsinogen activation or trypsin activity and seemed to involve endoplasmic reticulum stress as a consequence of misfolding (Heiko Witt et al., 2013).

It is also possible that reduced CPA1 secretion might cause predisposition to $\mathrm{CP}$ by other mechanisms. In this respect, we noted that procarboxypeptidase A (proCPA) often forms complexes with proelastases in the mammalian pancreas (Szabó, Pilsak, Bence, Witt, \& Sahin-Tóth, 2016). Consequently, changes in CPA1 levels in the secretory pathway and pancreatic juice might have a significant impact on proelastases; possibly facilitating ectopic elastase activation and thereby contributing to pancreatic injury.

CELA2A and CELA3B bind to proCPA1 and CELA3B also binds to proCPA2 (M Moulard, Kerfelec, Mallet, \& Chapus, 1989; Maxime Moulard, Michon, Kerfelec, \& Chapus, 1990; Pascual et al., 1989; Szabó et al., 2016). Even though CELA3A is 92\% identical with 
CELA3B in its primary structure, it does not form tight complexes with proCPA1 or proCPA2(Szabó et al., 2016). It is known that a major determinant of binding affinity was amino acid 241, which is Gly in CELA3A and Ala in CELA3B. Mutation p.G241A in CELA3A increases whereas mutation p.A241G in CELA3B reduces binding to proCPA1 (Szabó et al., 2016). Notably, position 241 is polymorphic in both elastases with minor allele frequencies of about $2 \%$ in subjects of European origin. This genetic variation should translate to individual differences in complex formation between proelastases and proCPA1. More importantly, the polymorphic nature of amino-acid 241 offers the unique opportunity to perform a genetic association study to investigate whether changes in complex formation between proelastases and procarboxypeptidases affect $\mathrm{CP}$ risk. 


\section{Aims}

\subsection{ScheBo Pancreatic Elastase 1 Test Study}

Determination of fecal pancreatic elastase content by ELISA is a reliable, non-invasive clinical test for assessing exocrine pancreatic function. Despite the widespread use of commercial tests, their exact molecular targets remain poorly characterized.

Specific aims:

- This study was undertaken to clarify which human pancreatic elastase isoforms are detected by the ScheBo Pancreatic Elastase 1 Stool Test and whether naturally-occurring genetic variants influence the performance of this test. Using well-defined recombinant pancreatic proteinases we characterized the detection specificity of the ScheBo ELISA test.

\subsection{Genetic analysis study}

Normally proCELA3A binds poorly to procarboxypeptidases due to the presence of Gly241, whereas proCELA3B which contains Ala241 forms tight complexes (Szabó et al., 2016) Individuals carrying heterozygous p.G241A polimorfic variant in CELA3A should have increased complex levels in their pancreatic secretions. Conversely, subjects with the p.A241G variant in CELA3B should exhibit decreased complex formation and higher levels of free zymogens. Should CP risk be elevated by decreased complex formation, one would expect to observe underrepresentation of the CELA3A p.G241A variant and/or enrichment of the CELA3B p.A241G variant in a cohort of CP patients versus population controls.

\section{Specific aims:}

- In this study we performed a genetic association study to investigate whether changes in complex formation between proelastases and procarboxypeptidases affect on the risk of CP. In addition to the position 241 variants we wanted to discover other elastase mutations which might have been associated with pancreatic diseases. 


\section{Materials and methods}

\subsection{Experiments for both study}

\subsubsection{Nomenclature}

Coding DNA numbering starts with the first nucleotide of the translation initiator codon which was designated c.1. Amino acid residues were numbered starting with the initiator methionine of the primary translation product. Note that the CELA3A and CELA3B genomic reference sequences (chromosome 1 primary assembly, NC_000001.11) for CELA3A contains the minor alleles at positions c.722 (p.241) and c.795+21. In CELA3B positions c.780 (p.260) and c. $795+21$ represent minor alleles. To better contrast position 241 between the two genes, we used the major c.722G allele (p.G241) as a reference for CELA3A and designated the variant at this position as c.722G>C (p.G241A). Amino-acid variants are numbered starting with the initiator methionine of the primary translation products of CELA3A and CELA3B.

\subsubsection{Plasmid construction and mutagenesis}

Expression plasmids for human elastases CELA2A, CELA3A, CELA3B and chymotrypsins CTRB1, CTRB2, CTRC and CTRL1 constructed in the pcDNA3.1(-) vector (Szabó et al., 2016) and for human trypsins PRSS1, PRSS2 and PRSS3 in the pTrapT7 vector were described previously (Kukor, Tóth, \& Sahin-Tóth, 2003; Sahin-Tóth \& Tóth, 2000; Szmola, Kukor, \& Sahin-Tóth, 2003). The plasmids contain the coding DNA for the proenzyme (zymogen) form of the indicated pancreatic proteinases. Mutations in CELA3A and CELA3B were introduced by overlap extension PCR mutagenesis. The coding DNA for autolyzed forms of CELA3B carrying 9 His residues at their $\mathrm{C}$ terminus was created by gene synthesis and cloned into the pcDNA3.1(-) plasmid using EcoRI and BamHI restriction sites. In the CELA3B-9del construct the N-terminal 9 amino acids from Tyr18 to Ser26 were deleted. In the CELA3B-13del construct the N-terminal 13 amino acids from Tyr18 to Val30 were removed. 


\subsubsection{Cell culture and transfection}

For small scale expression studies, human embryonic kidney (HEK) 293T cells were grown in six-well tissue culture plates $\left(1.5 \times 10^{6}\right.$ cells per well) in Dulbecco's Modified Eagle Medium (DMEM) supplemented with $10 \%$ fetal bovine serum, $4 \mathrm{mM}$ glutamine and $1 \%$ penicillin/streptomycin, at $37{ }^{\circ} \mathrm{C}$ in a humidified atmosphere containing $5 \% \mathrm{CO}_{2}$. Transfections were performed with $4 \mu \mathrm{g}$ expression plasmid with $10 \mu \mathrm{L}$ Lipofectamine 2000 (Invitrogen, Carlsbad, CA, USA) in $2 \mathrm{~mL}$ DMEM. After overnight incubation cells were rinsed and covered with $2 \mathrm{~mL}$ Opti-MEM Reduced Serum Medium. The conditioned media were harvested after $48 \mathrm{~h}$.

\subsubsection{Enzyme activity measurements}

Enzymatic activity of human CELA3A and CELA3B in the conditioned medium of transfected cells was determined using the Suc-Ala-Ala-Pro-Ala- $p$-nitroanilide substrate (Boros et al., 2017). To activate proelastases, aliquots of conditioned media (100 $\mu \mathrm{L})$ were supplemented with $10 \mu \mathrm{L}$ of $1 \mathrm{M}$ Tris- $\mathrm{HCl}(\mathrm{pH} 8.0)$ and $1 \mu \mathrm{L} 0.1 \mathrm{M} \mathrm{CaCl}_{2}$ and incubated with $100 \mathrm{nM}$ human cationic trypsin at $37{ }^{\circ} \mathrm{C}$ for $30 \mathrm{~min}$ (final concentrations). Activated elastases $(20 \mu \mathrm{L})$ were then mixed with $175 \mu \mathrm{L}$ assay buffer $\left(0.1 \mathrm{M}\right.$ Tris- $\mathrm{HCl}(\mathrm{pH} 8.0), 1 \mathrm{mM} \mathrm{CaCl}{ }_{2}$, $0.05 \%$ Tween 20 ) and elastase activity was measured by adding $5 \mu \mathrm{L}$ of $6 \mathrm{mM}$ substrate. The increase in absorbance at $405 \mathrm{~nm}$ was followed for $5 \mathrm{~min}$ in a microplate reader at $22{ }^{\circ} \mathrm{C}$. Rates of substrate cleavage were calculated from the linear portion of the curves and expressed in $\mathrm{mOD} / \mathrm{min}$ units.

\subsubsection{SDS-page}

Conditioned media $(180 \mu \mathrm{L})$ were precipitated with $10 \%$ trichloroacetic acid (final concentration); the precipitate was collected by centrifugation and resuspended in $20 \mu \mathrm{L}$ Laemmli sample buffer containing $100 \mathrm{mM}$ dithiothreitol, heat-denatured at $95{ }^{\circ} \mathrm{C}$ for $5 \mathrm{~min}$ and run on $15 \%$ SDS-polyacrylamide gels. The gels were stained with Coomassie Blue R250. Densitometric quantitation of bands was carried out with the Gel Doc XR+ gel documentation system and Image Lab software (Bio-Rad, Hercules, CA, USA). 


\subsubsection{Purification of pancreatic proteinases}

Human proelastases and chymotrypsinogens were expressed in transiently transfected HEK 293T cells and purified from the conditioned medium through their C-terminal His tags by nickel-affinity chromatography, as reported previously(Szabó et al., 2016). Human trypsinogens were expressed in E. coli as insoluble inclusion bodies. Refolding and purification on immobilized ecotin were performed according to a previously published protocol (Kukor et al., 2003)(Sahin-Tóth \& Tóth, 2000; Szmola et al., 2003). Concentrations of proenzyme solutions were determined on the basis of their UV absorbance at $280 \mathrm{~nm}$ using the following extinction coefficients, calculated with the web-based ProtParam tool (in $\mathrm{M}^{-}$ ${ }^{1} \cdot \mathrm{cm}^{-1}$ units): CELA2A 73,505; CELA3A 76,025; CELA3B 74,535; CELA3B mutant W79R 69,035; CTRB1 and CTRB2 47,605; CTRC 64,565; PRSS1 37,525; PRSS2 38,890; PRSS3 41,535. Proteinase solutions were diluted to $1 \mathrm{nM}$ working stocks in assay buffer ( $0.1 \mathrm{M}$ Tris$\mathrm{HCl}$ (pH 8.0), $1 \mathrm{mM} \mathrm{CaCl}_{2}$ and $0.05 \%$ Tween 20).

\subsubsection{Expression and purification of autolyzed CELA3B forms}

The CELA3B-9del and CELA3B-13del constructs were produced in HEK 293T cells and purified by nickel-affinity chromatography as described for the wild-type proenzyme (Szabó et al., 2016). N-terminal sequencing of the purified proteins revealed that $\sim 90 \%$ of the CELA3B-9del preparation contained the expected $\mathrm{N}$ terminus of Ser27 and minor contaminants with N-terminal amino acids of Asn31 (5\%) and Glu33 (5\%). The purified CELA3B-13del contained an approximately 50-50\% mixture of two forms; one with the expected $\mathrm{N}$ terminus of Asn31 and another species with an $\mathrm{N}$-terminal Glu33, indicating that the signal peptidase processed this construct at two sites. This preparation was suitable for the purpose of our experiments and further purification was not attempted. 


\subsection{Experiments with the ScheBo Pancreatic Elastase 1 test}

\subsubsection{Materials}

The ScheBo Pancreatic Elastase 1 Stool Test was purchased from the manufacturer. For some of the experiments we used the ScheBo Pancreatic Elastase 1 Serum Test which contains essentially the same ELISA components.

\subsubsection{ELISA assays}

Detection of human pancreatic proteinases by the ScheBo test was performed according to the manufacturer's instructions with the ready-to-use reagents supplied, as follows. The $5 \times$ wash buffer (phosphate buffered saline $(\mathrm{pH} 7.2)$ with unspecified detergent stock was diluted with water before use. Aliquots $(50 \mu \mathrm{L})$ of purified proteinases or conditioned media diluted in assay buffer $(0.1 \mathrm{M}$ Tris- $\mathrm{HCl}(\mathrm{pH} 8.0), 1 \mathrm{mM} \mathrm{CaCl} 2,0.05 \%$ Tween 20) were added to the ELISA strips containing an immobilized anti-elastase antibody (Figure 1). As blank, $50 \mu \mathrm{L}$ assay buffer was used. After $30 \mathrm{~min}$ incubation at $22{ }^{\circ} \mathrm{C}$, the enzyme solutions were removed from the wells. The wells were rinsed three times for 2 min each with $250 \mu \mathrm{L}$ wash buffer. An aliquot $(50 \mu \mathrm{L})$ of a biotinylated anti-elastase antibody complexed with peroxidase-conjugated streptavidin was added to the wells and incubated for $30 \mathrm{~min}$ in the dark at $22{ }^{\circ} \mathrm{C}$. The antibody solution was discarded and the wells were rinsed three times for $2 \mathrm{~min}$ each with $250 \mu \mathrm{L}$ wash buffer. For color development, $100 \mu \mathrm{L}$ 2,2'azino-bis(3-ethylbenzothiazoline-6-sulphonic acid) (ABTS) peroxidase substrate solution was added and incubated in the dark or $20 \mathrm{~min}$ at $22{ }^{\circ} \mathrm{C}$. The reaction was terminated by adding $100 \mu \mathrm{L}$ stop solution and incubating for $10 \mathrm{~min}$. The dark green ELISA signal (absorbance) was measured in a plate reader at $405 \mathrm{~nm}$. All assays were performed in duplicates. Data points plotted represent absorbance readings corrected for the average of two blank values. 


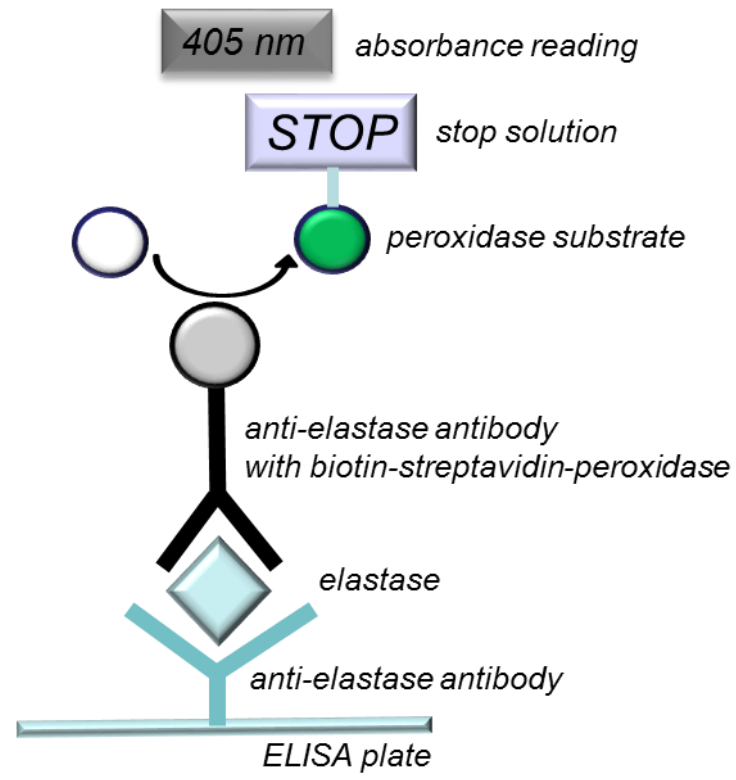

Figure 1. Schematic diagram of elastase detection by the sandwich ELISA method of the ScheBo Pancreatic Elastase 1 Stool Test. See Methods for details.

\subsection{Performing genetic study}

\subsubsection{Study Subjects}

De-identified genomic DNA samples were obtained from the registry of the Hungarian Pancreatic Study Group (ethical approval: TUKEB 22254-1/2012/EKU, biobanking approval: IF702-19/2012). Individuals in the registry were recruited from 11 Hungarian centers between 2012 and 2016 and all gave informed consent according to the ethical guidelines of the Declaration of Helsinki. The study was approved by the Institutional Review Board at Boston University ("Analysis of susceptibility genes in patients with chronic pancreatitis"; IRB number H-35382). A total of 225 unrelated patients with $\mathrm{CP}$, including 120 with alcoholic $\mathrm{CP}$ (ACP) and 105 with idiopathic CP (ICP) and 300 control subjects with no pancreatic disease were studied. Sequence analysis of CELA3A and CELA3B was successfully completed for 295 and 293 of the 300 control samples, respectively. Patient characteristics are summarized in Table 1. Diagnosis of CP was based on two or more of the following findings: history of recurrent acute pancreatitis, pancreatic calcification detected by CT or ultrasonography, and pancreatic ductal irregularities on endoscopic retrograde cholangiopancreatography (ERCP) or magnetic resonance cholangiopancreatography (MRCP) examinations. ACP was diagnosed when the patient history included alcohol consumption of more than $80 \mathrm{~g} /$ day (men) or 60 
g/day (women) for at least two years. ICP was diagnosed in the absence of precipitating or risk factors for pancreatitis, such as alcohol abuse, medications, trauma, metabolic disorders or infection. A representative sample of this cohort including 100 patients (49 ACP and 51 ICP) and 100 controls was previously characterized for the clinically common SPINK1 variants; the p.N34S variant was found in three ICP patients and in one control subject while the c.194+2T $>$ C variant was detected in two ACP and one ICP patients but not in controls .

\begin{tabular}{|l|c|c|c|c|c|c|c|c|}
\cline { 2 - 9 } & \multicolumn{2}{c|}{ ACP $\boldsymbol{n}=\mathbf{1 2 0}$} & \multicolumn{2}{c|}{ ICP $\boldsymbol{n} \mathbf{1 0 5}$} & \multicolumn{2}{c|}{ All CP $\boldsymbol{n}=\mathbf{2 2 5}$} & \multicolumn{2}{c|}{ Controls $\boldsymbol{n}=\mathbf{3 0 0}$} \\
\cline { 2 - 9 } & Male & Female & Male & Female & Male & Female & Male & Female \\
\cline { 2 - 9 } & $\mathbf{1 0 7}$ & $\mathbf{1 3}$ & $\mathbf{6 3}$ & $\mathbf{4 2}$ & $\mathbf{1 7 0}$ & $\mathbf{5 5}$ & $\mathbf{1 8 0}$ & $\mathbf{1 2 0}$ \\
\hline Age & $56 \pm 9$ & $51 \pm 8$ & $58 \pm 12$ & $61 \pm 14$ & $57 \pm 11$ & $59 \pm 14$ & $52 \pm 11$ & $52 \pm 13$ \\
\hline Age of onset & $47 \pm 11$ & $46 \pm 9$ & $49 \pm 12$ & $52 \pm 17$ & $48 \pm 11$ & $50 \pm 16$ & - & - \\
\hline
\end{tabular}

Table 1. Study population. Age represents age at recruitment. Mean \pm S.D. are shown. CP: chronic pancreatitis, ACP: alcoholic chronic pancreatitis, ICP: idiopathic chronic pancreatitis

\subsubsection{DNA Sequencing}

Primers were designed against intronic sequences flanking exon 7 in CELA3A and CELA3B. Primer sequences and amplicon sizes are given in Table 2. Polymerase chain reactions (PCR) were performed using 0.75 U HotStar Taq DNA polymerase (Qiagen, Valencia, CA, USA), $0.2 \mathrm{mM}$ dNTP, $5 \mu \mathrm{L} 5 \times$ Q-solution and $2.5 \mu \mathrm{L} 10 \times$ PCR buffer (Qiagen), $0.5 \mu \mathrm{M}$ primers, and 10-50 ng genomic DNA template in a volume of $25 \mu \mathrm{L}$. PCR reactions were started by a $15-\mathrm{min}$ initial heat activation at $95{ }^{\circ} \mathrm{C}$ followed by 35 cycles of 30 s denaturation at $94{ }^{\circ} \mathrm{C}, 30$-s annealing at $55^{\circ} \mathrm{C}$, and $40 \mathrm{~s}$ extension at $72{ }^{\circ} \mathrm{C}$; and finished by a final extension for $5 \mathrm{~min}$ at $72{ }^{\circ} \mathrm{C}$. Products of all PCR reactions were verified by $2 \%$ agarose gel electrophoresis. The PCR amplicons $(5 \mu \mathrm{L})$ were treated with $1 \mu \mathrm{L}$ FastAP Thermosensitive Alkaline Phosphatase and $0.5 \mu \mathrm{L}$ Exonuclease I (Thermo Fisher Scientific, Waltham, MA, USA) for $15 \mathrm{~min}$ at $37{ }^{\circ} \mathrm{C}$ and the reaction was stopped by heating the samples to $85^{\circ} \mathrm{C}$ for $15 \mathrm{~min}$. Sanger sequencing was performed using the reverse PCR primer as sequencing primer. Amplicons containing heterozygous deletion variants in intron 6 of CELA3A were also sequenced with the forward PCR primer. New variants were confirmed by a second independent PCR amplification and also by sequencing the other DNA strand. 


\begin{tabular}{|c|c|c|c|}
\hline $\begin{array}{l}\text { Primer } \\
\text { name }\end{array}$ & Primer Sequence $\left(5^{\prime} \rightarrow 3^{\prime}\right)$ & Amplicon & $\begin{array}{l}\text { Annealing } \\
\text { Temperature }\end{array}$ \\
\hline $\begin{array}{l}\text { CELA3A } \\
\text { x7 Forward }\end{array}$ & $\begin{array}{l}\text { TCA GAG GTG TCA AGT AAT GTC } \\
\text { AG }\end{array}$ & \multirow{2}{*}{$461 \mathrm{bp}$} & \multirow{2}{*}{$55^{\circ} \mathrm{C}$} \\
\hline $\begin{array}{l}\text { CELA3A } \\
\text { x7 Reverse }\end{array}$ & CTT GAT GGC TTC TGG GTG G & & \\
\hline $\begin{array}{l}\text { CELA3B } \\
\mathrm{x} 7 \text { Forward }\end{array}$ & TCA GAG GAG TCA GGT AAT GTC G & \multirow{2}{*}{$484 \mathrm{bp}$} & \multirow{2}{*}{$55^{\circ} \mathrm{C}$} \\
\hline $\begin{array}{l}\text { CELA3B } \\
\text { x7 Reverse }\end{array}$ & AAG TTC AGC TGT AGT TCC AAG C & & \\
\hline
\end{tabular}

Table 2. Oligonucleotide primers used for PCR amplification of exon 7 in CELA3A and CELA3B.

\section{RESULTS}

\subsection{ScheBo Pancreatic Elastase 1 Test results}

\subsubsection{The ScheBo Pancreatic Elastase 1 Stool Test detects elastase 3 isoforms CELA3A and CELA3B}

To determine the specificity of the ScheBo test, we recombinantly expressed and purified human pancreatic serine proteinases and performed ELISA assays according to the manufacturer's instructions. Elastases CELA3A and CELA3B were tested at $100 \mathrm{pM}$ final concentration while all other proteinases were tested at the 10 -fold higher $1 \mathrm{nM}$ concentration (Figure 2). We obtained strong signals for CELA3A and CELA3B whereas none of the other proteinases was detected to a significant extent. 


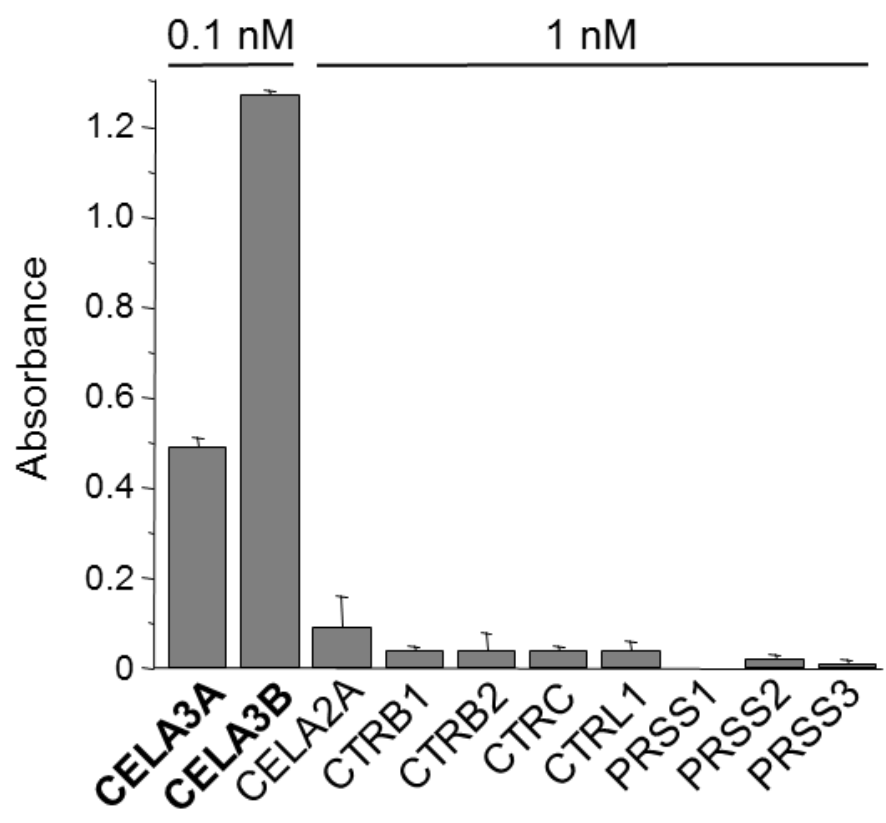

Figure 2. Detection of human pancreatic serine proteinases by the ScheBo Pancreatic Elastase 1 Stool Test. Proteinases were expressed recombinantly and purified as described in Methods. CELA3A and CELA3B were tested at $0.1 \mathrm{nM}$ final concentration whereas all other proteinases were tested at $1 \mathrm{nM}$ concentration. For CTRL1, conditioned medium diluted 1000-fold was used. Mean values with SD from three measurements are shown.

\subsubsection{Proelastases, active elastases and autolyzed elastase forms are measured with equal efficacy}

To characterize the detection of CELA3A and CELA3B by the ScheBo test in a more quantitative manner, we performed the ELISA assay using elastases over a concentration range from 20 to $200 \mathrm{pM}$. As shown in Figure 3A, CELA3B was detected on average 4.3-fold better (range 3.4 - 5.1-fold) than CELA3A over the concentration range tested. Identical signals were obtained when proelastases were compared to active elastases indicating that the test measures the zymogen and active forms with equal efficacy (Figure 3A). Autolyzed forms of CELA3B missing either 9 amino acids (9del) or 13 amino acids (13del) from the $\mathrm{N}$ terminus also produced ELISA signals identical to that of the intact CELA3B proelastase (Figure 3B). Since these results indicate that the ScheBo test does not discriminate between proelastase, active elastase and autolyzed elastase, in all subsequent experiments we used the proelastase forms of CELA3A and CELA3B. In a control experiment we also ruled out the unlikely confounding effect of the His tag on elastase expression and detection by the ScheBo test. Although data are not shown, tagged and untagged forms of CELA3A and CELA3B 
were secreted to comparable levels into the conditioned medium of transfected cells and gave identical ELISA signals.
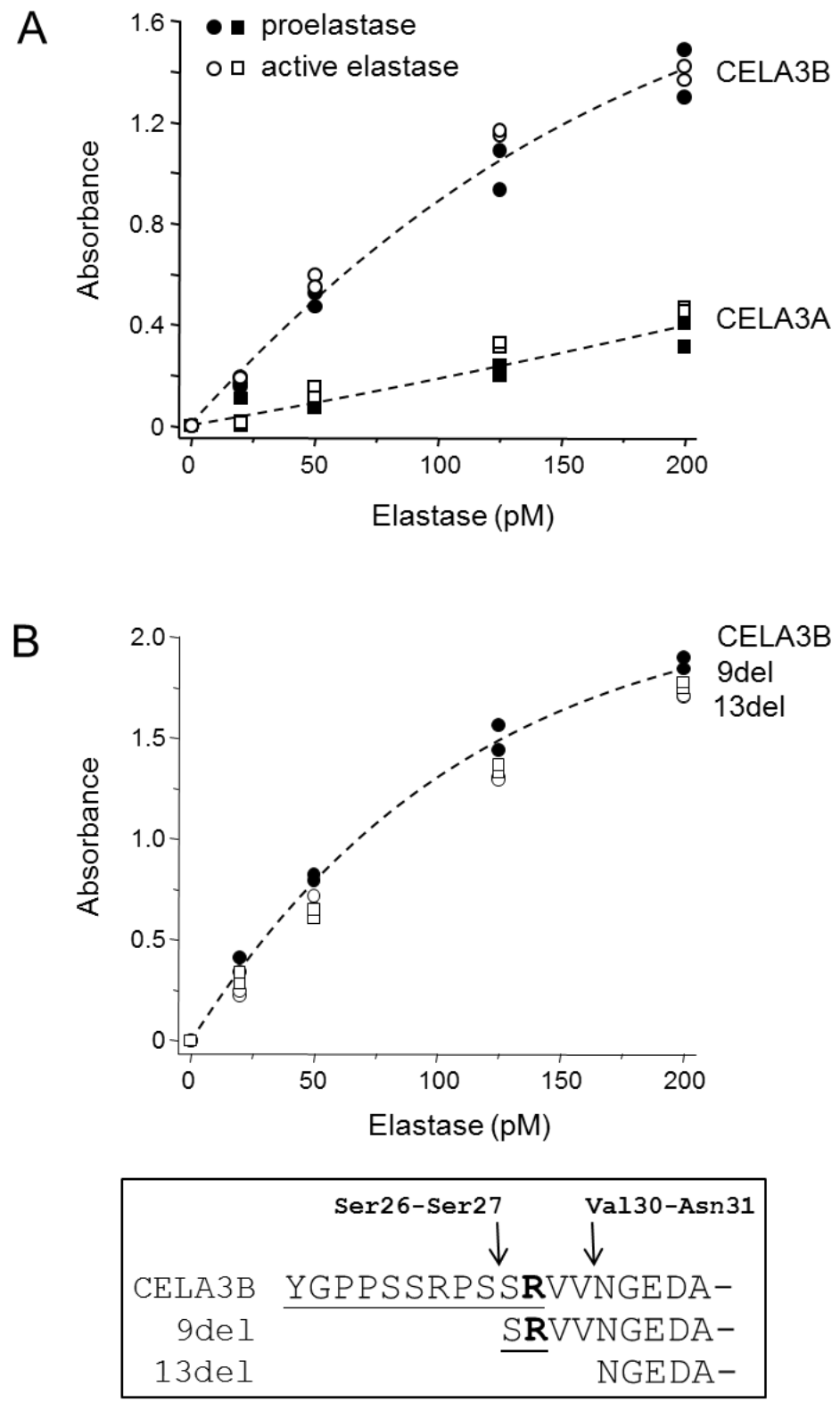

Figure 3. Detection of CELA3 isoforms by the ScheBo Pancreatic Elastase 1 Stool Test. (A) Comparison of test performance on proelastases versus active elastases in the 20-200 pM concentration range. $(B)$ Detection of autolyzed forms of CELA3B. The inset demonstrates the autolytic cleavage sites in the $N$-terminal part of CELA3B. Assays were performed in duplicate and both data points were plotted. 


\subsubsection{Effect of $C E L A 3 A$ and $C E L A 3 B$ genetic variants on the performance of the ScheBo test}

To identify genetic variants of CELA3A and $C E L A 3 B$ in the population, we interrogated the Exome Variant Server database of the NHLBI Exome Sequencing Project. When considering missense variants only with an allele frequency above $1 \%$, we found one CELA3A variant (G241A) and five CELA3B variants (W79R, Q134L, I209V, R210H and A241G). To evaluate whether common genetic variants of CELA3A and CELA3B might alter the performance of the ScheBo test, we purified these six variants and tested their detection in the ELISA assay. With the exception of the CELA3B W79R variant, none of the variants had an appreciable effect on signal development (Figure 4). Variant W79R was detected on average 1.4-fold (range 1.2 - 1.5-fold) better than wild-type CELA3B over the concentration range tested. However, considering that in most carriers the variant is heterozygous, this difference should have no meaningful impact on the clinical interpretation of the ScheBo test results. 

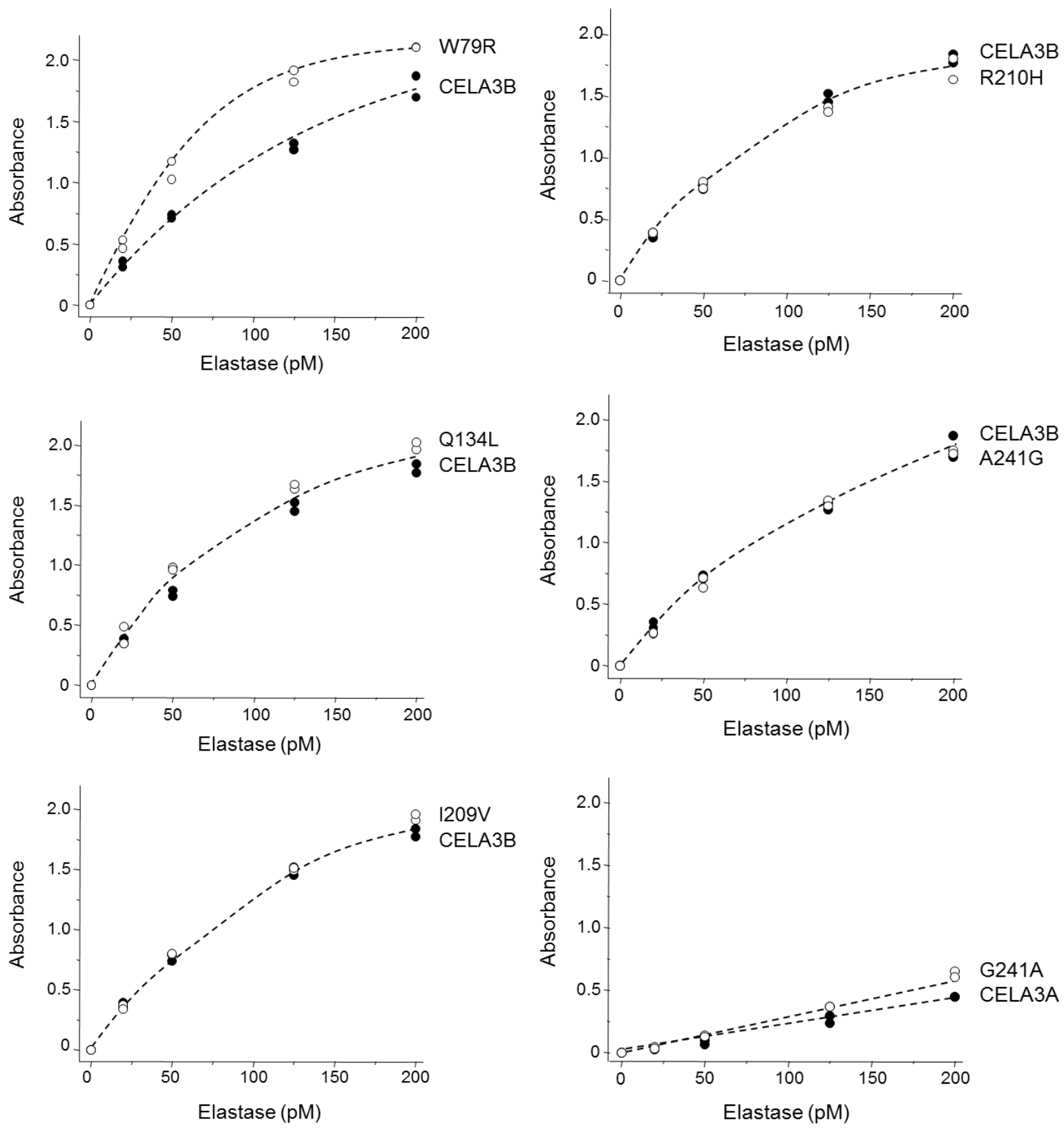

Figure 4. Detection of naturally occurring CELA3A and CELA3B variants by the ScheBo Pancreatic Elastase 1 Stool Test. Wild-type CELA3A, CELA3B and the indicated variants were purified and assayed in the 20-200 pM concentration range. Assays were performed in duplicate and both data points were plotted.

\subsubsection{Glu154 in CELA3B is a critical determinant of recognition by the ScheBo test}

CELA3A and CELA3B share 92\% identity at the amino-acid level yet CELA3B is detected circa 4-fold better than CELA3A by the ELISA assay. To identify the reason for this difference, we aligned the two isoforms (Figure 5A) and then individually mutated all divergent amino-acid positions in CELA3B to the corresponding CELA3A amino acid. 
Positions where differences occurred in neighboring amino acids were mutated en bloc. Overall 11 new CELA3B mutants were constructed and tested. For these qualitative screening experiments we used conditioned media of HEK 293T cells transfected with the mutant constructs. Remarkably, mutant E154K gave no ELISA signal whatsoever while all other mutants were robustly detected with some variations in signal yield (Figure 5B). Since the mutations may alter secretion and enzymatic activity of CELA3B, we also verified the expression of all mutants by SDS-PAGE and Coomassie staining (not shown) and by direct activity measurements after activation with trypsin. As shown in Figure 5C, all mutants, including E154K, exhibited measurable elastase activity and for the majority of mutants activity was comparable or even higher than that of the wild-type CELA3B. The higher activity of mutants S77R,S78D,W79L and D89N,R90L was due to higher elastase amounts secreted to the conditioned medium (not shown) and this was also consistent with the stronger ELISA signal (Figure 5B). Similarly, mutant A241G was secreted to higher levels (not shown) and produced a higher ELISA signal but this change was not obvious in the activity measurement as this mutation decreases catalytic activity of CELA3B (see below). Taken together, this initial screen conclusively identified Glu154 in CELA3B as a major determinant of recognition by the ScheBo test.

To confirm the importance of Glu154, we purified the E154K mutant and compared detection to wild-type CELA3B over a 20-200 pM concentration range. No signal was obtained with the mutant (Figure 6A). The ScheBo test uses a sandwich assay format with separate capturing and detection antibodies directed at different regions of the elastase molecules (see Figure 1). To ascertain whether the defect with the E154K mutant is at the level of capturing or detection, we eliminated the capturing step by immobilizing wild-type and mutant CELA3B to nickel plates (Ni-NTA HisSorb plate, Qiagen, Valencia, CA) via their His-tag. Under these assay conditions both elastase forms were detected comparably, indicating that mutation E154K interferes with the capturing step in the ELISA protocol (Figure 6B). Finally, structural modeling indicated that Glu154 is located on the surface of CELA3B far removed from the active site (Figure 6C). 


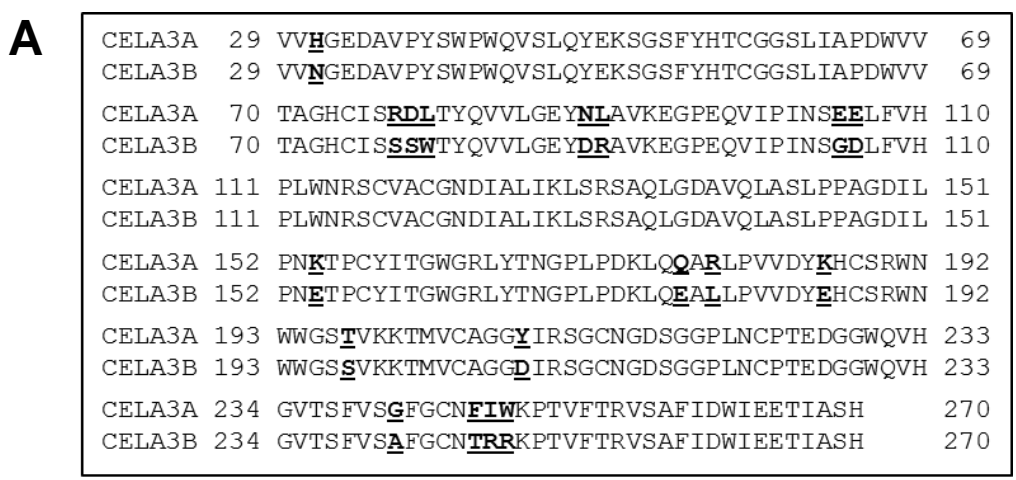

B
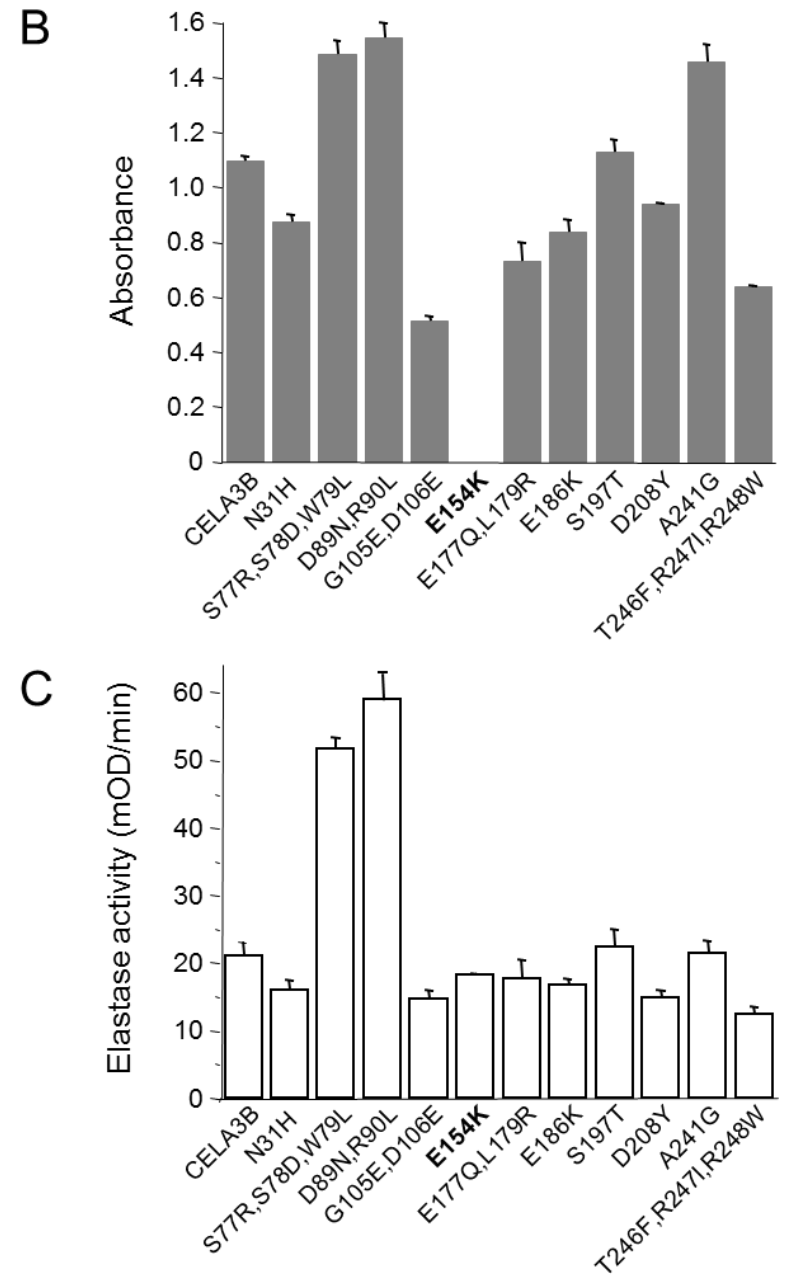

Figure 5. The effect of amino-acid differences between CELA3A and CELA3B on detection by the ScheBo Pancreatic Elastase 1 Stool Test (A) Alignment of the amino-acid sequences of the two human CELA3 isoforms. The active enzymes are shown; numbering starts with the initiator methionine of the pre-proelastases. Differences are underlined and emboldened. $(B)$ ELISA of CELA3B mutants carrying substitutions with the corresponding CELA3A amino acids. HEK $293 T$ cells were transfected with the indicated constructs and conditioned medium was collected after $48 \mathrm{~h}$. Elastase was assayed using 1000-fold diluted conditioned medium by the ScheBo test. See Methods for further details. (C) Elastase activity of CELA3B mutants measured in the conditioned medium after activation with trypsin. See Methods for experimental details. Mean values with SD from three experiments are shown. 
A

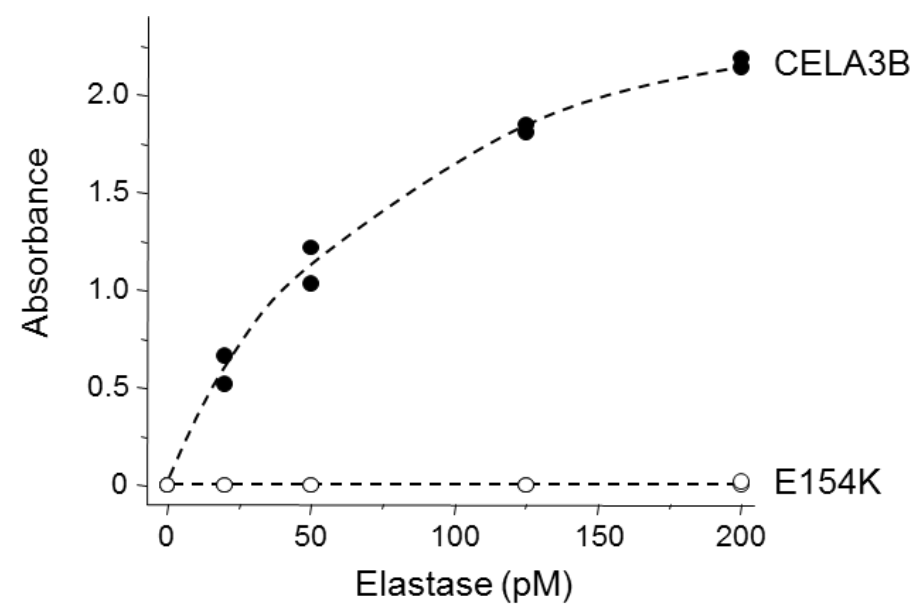

B Ni-NTA HisSorb Plate

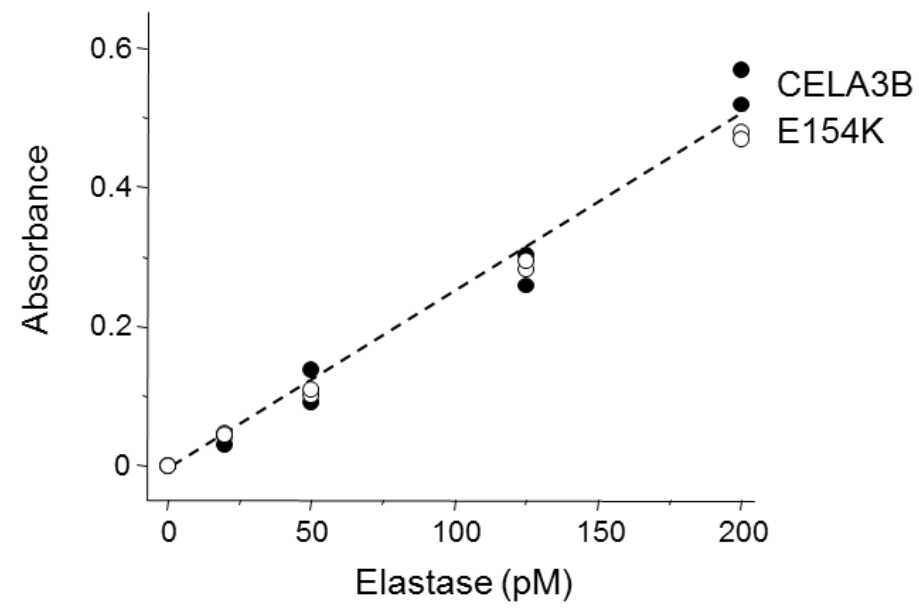

C

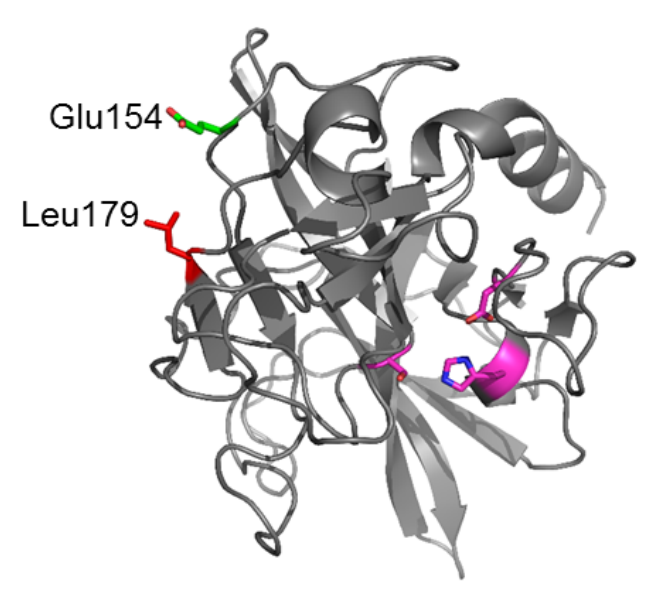

Figure 6. Detection of CELA3B mutant E154K by the ScheBo Pancreatic Elastase 1 Stool Test. (A) Purified wild-type and E154K mutant CELA3B were assayed over the 20-200 pM concentration range. (B) Purified wild-type and E154K mutant CELA3B were immobilized through their C-terminal His-tags to Ni-NTA HisSorb Plates (Qiagen) and detected with the biotinylated antibody-streptavidin-peroxidase complex form the ScheBo test. Assays were performed in duplicate and both data points were plotted. (C) Structural model of human CELA3B indicating the positions of Glu154 (green) and nearby Leu179 (red). Also shown for 
reference are the residues of the catalytic triad (magenta). The structural model for active CELA3B was generated by the SWISS-MODEL protein structure homology-modeling server using porcine elastase as template. The image was rendered with PyMOL (Schrödinger, Cambridge, MA).

\subsubsection{Mutations of Lys154 and nearby Arg179 improve detection of CELA3A}

The experiments presented above strongly indicated that detection of CELA3A should be improved by changing the Lys154 residue to Glu. Surprisingly, however, when the CELA3A mutant K154E was purified and tested, no improvement in detection was observed over wild-type CELA3A (Figure 7A). To explain these puzzling observations, we speculated that the presence of another divergent amino-acid that lies in proximity interferes with the recognition of Glu154 in the CELA3A K154E mutant. Inspection of the CELA3B structural model indicated that amino acid 179, which is Arg in CELA3A and Leu in CELA3B, might be important in this regard (see Figure 6C). Indeed, when mutations K154E and R179L were introduced simultaneously in CELA3A, the ELISA signal was increased by about 2.5 -fold and approximated that of CELA3B (Figure 7B).
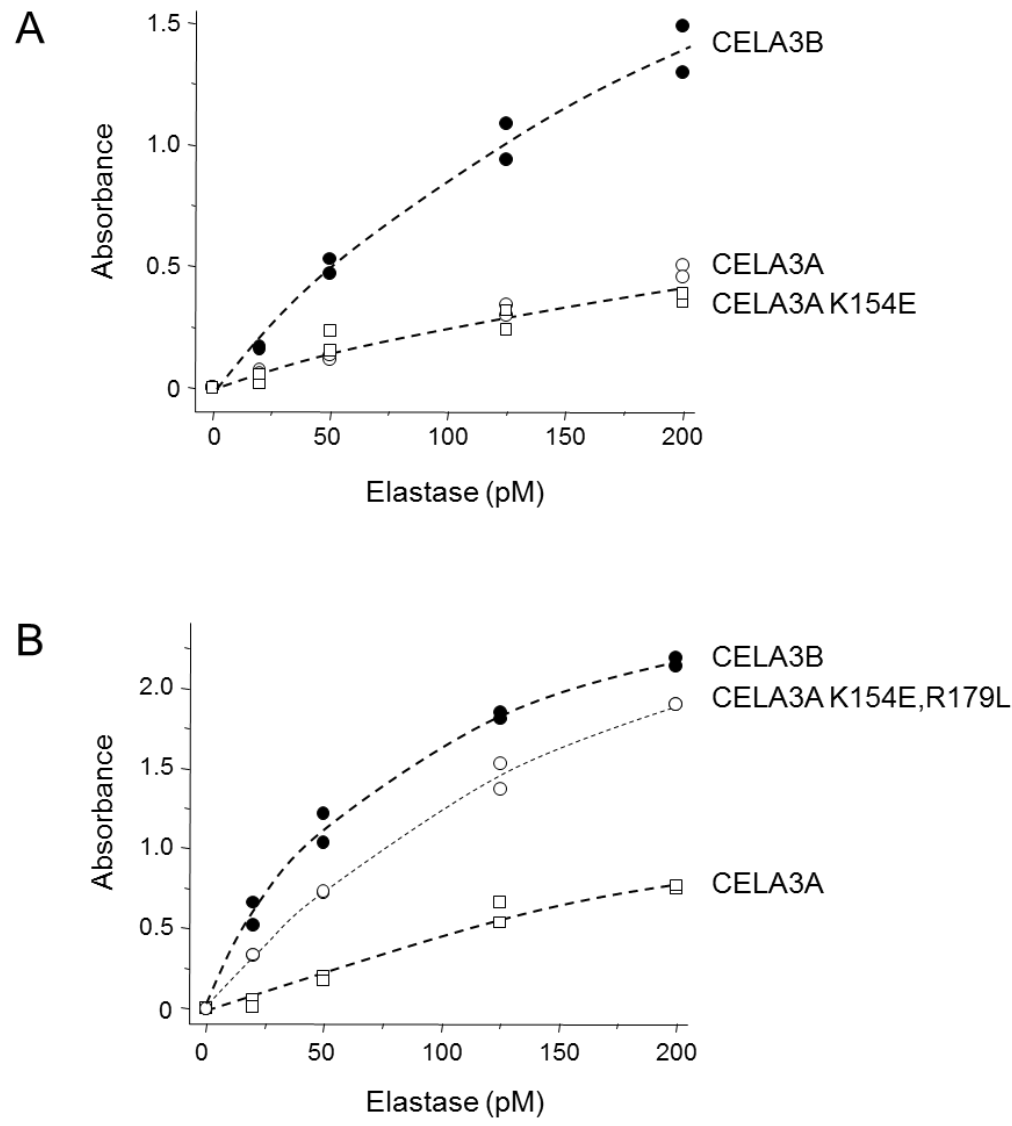
Figure 7. Detection of CELA3A mutant K154E and double mutant K154E,R179L by the ScheBo Pancreatic Elastase 1 Stool Test. Wild-type CELA3A, CELA3B and the indicated CELA3A variants were purified and assayed in the 20-200 pM concentration range. Assays were performed in duplicate and both data points were plotted.

\subsubsection{DNA Sequence Analysis of Exon 7 of Human CELA3A and CELA3B}

To investigate whether changes in complex formation between human procarboxypeptidases and proelastases alter risk for $\mathrm{CP}$, we investigated the frequency of variants c.722G $>\mathrm{C}$ (p.G241A) in $C E L A 3 A$ and c.722C $>\mathrm{G}$ (p.A241G) in $C E L A 3 B$ in subjects with $\mathrm{CP}$ and controls without pancreatic disease. We sequenced exon 7 and flanking intronic regions of $C E L A 3 A$ and $C E L A 3 B$ in 225 patients and 300 controls from the registry of the Hungarian Pancreatic Study Group. This CP cohort consisted of 120 alcoholic chronic pancreatitis (ACP) and 105 idiopathic chronic pancreatitis (ICP) patients. Sequence analysis of CELA3A and CELA3B was successfully completed for all patient samples and for 295 and 293 of the 300 control samples, respectively. In CELA3A we found 8 variants which included 4 intronic variants, 3 synonymous variants and 1 non-synonymous (missense) variant (Table 3). Synonymous variants c.750C $>$ T (p.P250=) and c.753G $>$ A (p.T251=) were found in complete linkage disequilibrium. In $C E L A 3 B$ we detected 13 variants which included 6 intronic variants, 3 synonymous variants, 3 non-synonymous (missense) variants and a geneconversion event resulting in five nucleotide alterations that changed three amino-acids at the protein level (Table 3). Synonymous variants c.699T $>C$ (p.H233=) and c.702C $>$ T (p.G234=) were found in the same ACP patient.

\begin{tabular}{|c|c|c|c|c|c|c|c|}
\hline CELA3A & Nucleotide Change & AminoAcid Change & Patient Alleles & Control Alleles & OR & $p$ Value & $95 \% \mathrm{CI}$ \\
\hline Intron 6 & c. $643-78 \mathrm{~T}>\mathrm{C}$ & - & $81 / 450(18 \%)$ & $124 / 590(21 \%)$ & 0.83 & 0.23 & $0.6-1.13$ \\
\hline Intron 6 & c.643-17delC & - & $21 / 450(4.7 \%)$ & $24 / 590(4.1 \%)$ & 1.5 & 0.64 & $0.63-2.1$ \\
\hline Intron 6 & c.643-13_12delCT & - & $3 / 450(0.7 \%)$ & $5 / 590(0.8 \%)$ & 0.79 & 0.74 & $0.19-3.3$ \\
\hline Exon 7 & c. $699 \mathrm{C}>\mathrm{T}$ & p.H233= & $1 / 450(0,2 \%)$ & $0 / 590(0 \%)$ & - & - & - \\
\hline Exon 7 & c. $722 \mathrm{G}>\mathrm{C}$ & p.G241A & $9 / 450(2 \%)$ & $15 / 590(2.5 \%)$ & 0.78 & 0.57 & $0.34-1.8$ \\
\hline Exon 7 & c. $750 \mathrm{C}>\mathrm{T}$ & p.P250= & $\begin{array}{l}105 / 450 \\
(23.3 \%)\end{array}$ & $157 / 59(26.6 \%)$ & 0.84 & 0.23 & $0.63-1.12$ \\
\hline Exon 7 & c. $753 \mathrm{G}>\mathrm{A}$ & p.T251= & $\begin{array}{l}105 / 450 \\
(23.3 \%)\end{array}$ & $157 / 590(26.6 \%)$ & 0.84 & 0.23 & $0.63-1.12$ \\
\hline Intron 7 & c. $795+21 \mathrm{C}>\mathrm{A}$ & - & $\begin{array}{c}321 / 450 \\
(71.3 \%)\end{array}$ & $399 / 590(67.6 \%)$ & 1.19 & 0.2 & $0.91-1.56$ \\
\hline CELA3B & Nucleotide Change & AminoAcid Change & Patient Alleles & Control Alleles & OR & $p$ Value & $95 \% \mathrm{CI}$ \\
\hline Intron 6 & c. $643-26 \mathrm{C}>\mathrm{T}$ & - & $20 / 450(4.4 \%)$ & $25 / 586(4.3 \%)$ & 1.04 & 0.89 & $0.57-1.91$ \\
\hline Intron 6 & c. $643-9 \mathrm{C}>\mathrm{T}$ & - & $2 / 450(0.4 \%)$ & $0 / 586(0 \%)$ & - & - & - \\
\hline Intron 6 & c. $643-7 \mathrm{G}>\mathrm{T}$ & - & $72 / 450(16 \%)$ & $125 / 586(21.3 \%)$ & 0.7 & $0.03 *$ & $0.51-0.97$ \\
\hline
\end{tabular}




\begin{tabular}{|c|c|c|c|c|c|c|c|}
\hline Exon 7 & c. $694 \mathrm{G}>\mathrm{C}$ & p.V232L & $1 / 450(0.2 \%)$ & $1 / 586(0.2 \%)$ & 1.3 & 0.85 & $0.08-20.8$ \\
\hline Exon 7 & c. $699 \mathrm{~T}>\mathrm{C}$ & p.H233= & $1 / 450(0.2 \%)$ & $0 / 586(0 \%)$ & - & - & - \\
\hline Exon 7 & c. $702 \mathrm{C}>\mathrm{T}$ & p.G234= & $1 / 450(0.2 \%)$ & $0 / 586(0 \%)$ & - & - & - \\
\hline Exon 7 & c. $722 \mathrm{C}>\mathrm{G}$ & p.A241G & $10 / 450(2.2 \%)$ & $9 / 586(1.5 \%)$ & 146 & 0.42 & 0.59-3.61 \\
\hline Exon 7 & $\begin{array}{l}\text { c. } 736 \mathrm{~A}>\mathrm{T}, \\
\text { c. } 737 \mathrm{C}>\mathrm{T}, \\
\text { c. } 739 \mathrm{C}>\mathrm{A}, \\
\text { c. } 740 \mathrm{G}>\mathrm{T}, \\
\text { c. } 742 \mathrm{~A}>\mathrm{T}\end{array}$ & $\begin{array}{l}\text { p.T246F, } \\
\text { p.R247I, } \\
\text { p.R248W }\end{array}$ & $1 / 450(0.2 \%)$ & $0 / 586(0 \%)$ & - & - & - \\
\hline Exon 7 & c. $740 \mathrm{G}>\mathrm{C}$ & p.R247P & $0 / 450(0 \%)$ & $1 / 586(0,2 \%)$ & - & - & - \\
\hline Exon 7 & c. $780 \mathrm{~T}>\mathrm{C}$ & p. $.260=$ & $\begin{array}{l}445 / 450 \\
(98.9 \%)\end{array}$ & $580 / 586(99 \%)$ & 0.92 & 0.89 & $0.28-3.03$ \\
\hline Intron 7 & c. $795+21 \mathrm{C}>\mathrm{A}$ & - & $\begin{array}{r}340 / 450 \\
(75.66 \%)\end{array}$ & $413 / 586(70.5 \%)$ & 1.29 & 0.07 & $0.97-1.71$ \\
\hline Intron 7 & c. $795+22 \mathrm{G}>\mathrm{A}$ & - & $1 / 450(0.2 \%)$ & $1 / 586(0.2 \%)$ & 1.3 & 0.85 & $0.08-20.88$ \\
\hline Intron 7 & c. $795+73 \mathrm{G}>\mathrm{A}$ & _ & $0 / 450(0 \%)$ & $1 / 586(0.2 \%)$ & - & _ & \\
\hline
\end{tabular}

Table 3. Allele frequency of CELA3A and CELA3B variants in patients with chronic pancreatitis and controls without pancreatic disease. Variants affecting position 241 are highlighted in bold. OR, odds ratio; CI, confidence interval. Asterisk indicates significant association

When allele frequency was considered, distribution of the variants between patients and controls showed a significant difference only for the CELA3B variant c.643-7G>T in intron 6, which occurred with an allele frequency of $16 \%$ in patients and $21.3 \%$ in controls $(\mathrm{OR}=0.7 ; 95 \%$ CI $0.51-0.97 ; p=0.03$; Table 3$)$. Subgroup analysis revealed that the association was driven by the ACP cohort $(\mathrm{OR}=0.59,95 \% \mathrm{CI}=0.39-0.89, \mathrm{p}=0.01)$ while it was not significant in ICP patients ( $p=0.4$; Table 4 and Table 5) Importantly, neither p.G241A in CELA3A nor p.A241G in CELA3B was significantly enriched in patients or controls. Novel missense variants identified in $C E L A 3 B$ were rare; the heterozygous c.694G >C (p.V232L) variant was found in one ACP patient and one control, whereas the heterozygous c.740G >C (p.R247P) variant was found in one control subject only. Both subjects with the p.V232L variant also carried a heterozygous c.643-7G>T CELA3B variant, while the subject with the p.R247P variant carried a heterozygous c.643$26 \mathrm{C}>\mathrm{T} C E L A 3 B$ variant. An unexpected observation in CELA3B was a heterozygous gene conversion event detected in a patient with ICP. A minimum of seven nucleotides in $C E L A 3 B$ between c.736 and c.742 was converted with the corresponding CELA3A sequence. This resulted in five nucleotide changes (c.736A $>\mathrm{T}$, 
c.737C > c c.739C >A, c.740G $>$ T, c.742A > T) and three amino-acid changes (p.T246F, p.R247I, p.R248W) in CELA3B (Figure 8).

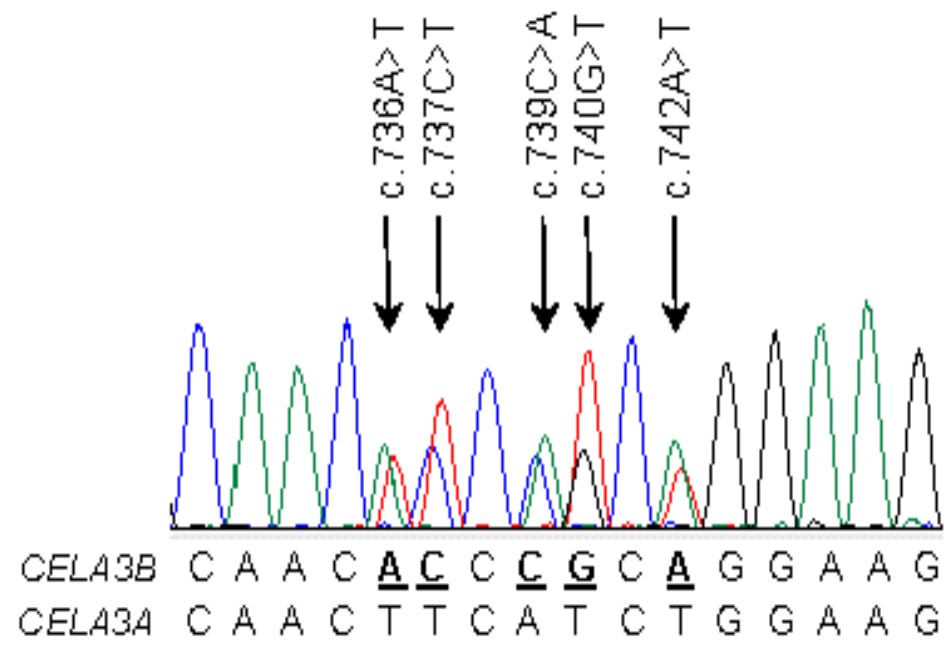

Figure 8. Gene conversion between CELA3A (donor) and CELA3B (acceptor). Electropherogram of CELA3B exon 7 in the Hungarian idiopathic chronic pancreatitis (ICP) patient. Heterozygous variations are indicated by arrows. Alignment of the relevant sequence tracts of CELA3A and CELA3B are also shown. CELA, human chymotrypsin-like elastase.

\begin{tabular}{|c|c|c|c|c|c|c|c|}
\hline CELA3A & Nucleotide Change & AminoAcid Change & ACP Patient Alleles & Control Alleles & OR & $p$ Value & $95 \% \mathrm{CI}$ \\
\hline Intron 6 & c. $643-78 \mathrm{~T}>\mathrm{C}$ & - & $43 / 240(17.9 \%)$ & $124 / 590(21 \%)$ & 0.82 & 0.31 & $0.56-1.2$ \\
\hline Intron 6 & c. $643-17 \mathrm{delC}$ & - & $13 / 240(5.4 \%)$ & $24 / 590(4.1 \%)$ & 1.35 & 0.4 & $0.68-2.7$ \\
\hline Intron 6 & c.643-13_12delCT & - & $1 / 240(0.4 \%)$ & $5 / 590(0.8 \%)$ & 0.49 & 0.52 & $0.06-4.21$ \\
\hline Exon 7 & c. $722 \mathrm{G}>\mathrm{C}$ & p.G241A & $4 / 240(1.7 \%)$ & $15 / 590(2.5 \%)$ & 0.65 & 0.45 & $0.21-1.98$ \\
\hline Exon 7 & c. $750 \mathrm{C}>\mathrm{T}$ & p.P250= & $57 / 240(23.8 \%)$ & $157 / 59(26.6 \%)$ & 0.86 & 0.4 & $0.60-1.22$ \\
\hline Exon 7 & c. $753 \mathrm{G}>\mathrm{A}$ & p.T251= & $57 / 240(23.8 \%)$ & $157 / 590(26.6 \%)$ & 0.86 & 0.4 & $0.60-1.22$ \\
\hline Intron 7 & c. $795+21 \mathrm{C}>\mathrm{A}$ & - & $167 / 240(69.6 \%)$ & $399 / 590(67.6 \%)$ & 1.1 & 0.58 & $0.79-1.51$ \\
\hline CELA3B & Nucleotide Change & AminoAcid Change & ACP Patient Alleles & Control Alleles & OR & $\begin{array}{c}p \\
\text { Value }\end{array}$ & $95 \% \mathrm{CI}$ \\
\hline Intron 6 & c. $643-26 \mathrm{C}>\mathrm{T}$ & - & $13 / 240(5.4 \%)$ & $25 / 586(4.3 \%)$ & 1.29 & 0.48 & $0.65-2.56$ \\
\hline Intron 6 & c. $643-9 \mathrm{C}>\mathrm{T}$ & - & $2 / 240(0.8 \%)$ & $0 / 586(0 \%)$ & - & - & - \\
\hline Intron 6 & c. $643-7 \mathrm{G}>\mathrm{T}$ & - & $33 / 240(13.8 \%)$ & $125 / 586(21.3 \%)$ & 0.59 & $0.01 *$ & $0.39-0.89$ \\
\hline Exon 7 & c. $694 \mathrm{G}>\mathrm{C}$ & p.V232L & $1 / 240(0.4 \%)$ & $1 / 586(0.2 \%)$ & 2.45 & 0.53 & $\begin{array}{l}0.15- \\
39.29\end{array}$ \\
\hline Exon 7 & c. $699 \mathrm{~T}>\mathrm{C}$ & p.H233= & $1 / 240(0.4 \%)$ & $0 / 586(0 \%)$ & - & - & - \\
\hline Exon 7 & c. $702 \mathrm{C}>\mathrm{T}$ & p.G234= & $1 / 240(0.4 \%)$ & $0 / 586(0 \%)$ & - & - & - \\
\hline Exon 7 & c. $722 \mathrm{C}>\mathrm{G}$ & p.A241G & $5 / 240(2.1 \%)$ & 9/586 (1.5\%) & 1.37 & 0.58 & $0.45-4.11$ \\
\hline Exon 7 & c. $780 \mathrm{~T}>\mathrm{C}$ & p.I260= & $237 / 240(98.8 \%)$ & $580 / 586(99 \%)$ & 0.82 & 0.78 & $0.20-3.29$ \\
\hline Intron 7 & c. $795+21 \mathrm{C}>\mathrm{A}$ & - & $179 / 240(74.6 \%)$ & $\begin{array}{l}413 / 586 \\
(70.5 \%)\end{array}$ & 1.23 & 0.24 & $0.88-1.73$ \\
\hline Intron 7 & c. $795+22 \mathrm{G}>\mathrm{A}$ & - & $1 / 240(0.4 \%)$ & $1 / 586(0.2 \%)$ & 2.45 & 0.53 & $\begin{array}{l}0.15- \\
39.29\end{array}$ \\
\hline
\end{tabular}


Table 4. Allele frequency of CELA3A and CELA3B variants in patients with alcoholic chronic pancreatitis (ACP) and controls without pancreatic disease. Variants affecting position 241 are highlighted in bold. OR, odds ratio; CI, confidence interval. Asterisk indicates significant association

\begin{tabular}{|c|c|c|c|c|c|c|c|}
\hline CELA3A & Nucleotide Change & $\begin{array}{c}\text { AminoAcid } \\
\text { Change }\end{array}$ & Patient Alleles & $\begin{array}{c}\text { Control } \\
\text { Alleles } \\
\end{array}$ & OR & $\begin{array}{c}p \\
\text { Value } \\
\end{array}$ & $\begin{array}{c}95 \% \\
\text { CI }\end{array}$ \\
\hline Intron 6 & c. $643-78 \mathrm{~T}>\mathrm{C}$ & - & $38 / 210(18.1 \%)$ & $\begin{array}{c}124 / 590 \\
(21 \%)\end{array}$ & 0.83 & 0.37 & $\begin{array}{c}0.56- \\
1.24\end{array}$ \\
\hline Intron 6 & c.643-17delC & - & $8 / 210(3.8 \%)$ & $\begin{array}{l}24 / 590 \\
(4.1 \%)\end{array}$ & 0.93 & 0.87 & $\begin{array}{l}0.42- \\
2.11\end{array}$ \\
\hline Intron 6 & c.643-13_12delCT & - & $2 / 210(1 \%)$ & $5 / 590(0.8 \%)$ & 1.13 & 0.89 & $\begin{array}{l}0.22- \\
5.84\end{array}$ \\
\hline Exon 7 & c. $699 \mathrm{C}>\mathrm{T}$ & p.H233= & $1 / 210(0.5 \%)$ & $0 / 590(0 \%)$ & - & - & - \\
\hline Exon 7 & c.722G $>C$ & p.G241A & $5 / 210(2.4 \%)$ & $\begin{array}{l}15 / 590 \\
(2.5 \%)\end{array}$ & 0.93 & 0.89 & $\begin{array}{c}0.34 \\
2.61\end{array}$ \\
\hline Exon 7 & c. $750 \mathrm{C}>\mathrm{T}$ & p.P250= & $48 / 210(22.9 \%)$ & $\begin{array}{l}157 / 590 \\
(26.6 \%)\end{array}$ & 0.82 & 0.29 & $\begin{array}{l}0.56- \\
1.18\end{array}$ \\
\hline Exon 7 & c. $753 \mathrm{G}>\mathrm{A}$ & p.T251= & $48 / 210(22.9 \%)$ & $\begin{array}{l}157 / 590 \\
(26.6 \%)\end{array}$ & 0.82 & 0.29 & $\begin{array}{c}0.56- \\
1.18\end{array}$ \\
\hline Intron 7 & c. $795+21 \mathrm{C}>\mathrm{A}$ & - & $154 / 210(73.3 \%)$ & $\begin{array}{l}399 / 590 \\
(67.6 \%) \\
\end{array}$ & 1.32 & 0.13 & $\begin{array}{c}0.93- \\
1.87 \\
\end{array}$ \\
\hline CELA3B & Nucleotide Change & $\begin{array}{l}\text { AminoAcid } \\
\text { Change }\end{array}$ & Patient Alleles & $\begin{array}{l}\text { Control } \\
\text { Alleles }\end{array}$ & OR & $\begin{array}{c}p \\
\text { Value }\end{array}$ & $\begin{array}{l}95 \% \\
\text { CI }\end{array}$ \\
\hline Intron 6 & c. $643-26 \mathrm{C}>\mathrm{T}$ & - & $7 / 210(3.3 \%)$ & $\begin{array}{l}25 / 586 \\
(4.3 \%)\end{array}$ & 0.77 & 0.56 & $\begin{array}{l}0.33- \\
1.82\end{array}$ \\
\hline Intron 6 & c. $643-7 \mathrm{G}>\mathrm{T}$ & - & $39 / 210(18.6 \%)$ & $\begin{array}{l}125 / 586 \\
(21.3 \%)\end{array}$ & 0.84 & 0.4 & $\begin{array}{c}0.56- \\
1.26\end{array}$ \\
\hline Exon 7 & c. $722 \mathrm{C}>\mathrm{G}$ & p.A241G & $5 / 210(2.4 \%)$ & $9 / 586(1.5 \%)$ & 1.56 & 0.43 & $\begin{array}{c}0.52- \\
4.72\end{array}$ \\
\hline Exon 7 & $\begin{array}{c}\text { c. } 736 \mathrm{~A}>\mathrm{T}, \text { c } .737 \mathrm{C}>\mathrm{T}, \mathrm{c} .739 \mathrm{C}>\mathrm{A}, \\
\text { c. } 740 \mathrm{G}>\mathrm{T}, \mathrm{c} .742 \mathrm{~A}>\mathrm{T}\end{array}$ & $\begin{array}{l}\text { p.T246F, } \\
\text { p.R247I, } \\
\text { p.R248W }\end{array}$ & $1 / 210(0.5 \%)$ & $0 / 586(0 \%)$ & - & - & - \\
\hline Exon 7 & c. $780 \mathrm{~T}>\mathrm{C}$ & p.I260= & $208 / 210(99 \%)$ & $\begin{array}{c}580 / 586 \\
(99 \%)\end{array}$ & 1.08 & 0.93 & $\begin{array}{l}0.22- \\
5.37\end{array}$ \\
\hline Intron 7 & c. $795+21 \mathrm{C}>\mathrm{A}$ & - & $161 / 210(76.7 \%)$ & $\begin{array}{l}413 / 586 \\
(70.5 \%)\end{array}$ & 1.38 & 0.09 & $\begin{array}{c}0.96- \\
1.98\end{array}$ \\
\hline
\end{tabular}

Table 5. Allele frequency of CELA3A and CELA3B variants in patients with idiopathic chronic pancreatitis (ICP) and controls without pancreatic disease. Variants affecting position 241 are highlighted in bold. OR, odds ratio; CI, confidence interval.

Genotypes were also analyzed for common variants using dominant and recessive models but no significant differences were found between CP patients and controls (Table 6). In subgroup analysis of variant c.643-7G $>\mathrm{T}$ genotypes using a dominant model (GT plus TT in patients versus controls) we confirmed the underrepresentation of this variant in ACP patients ( $\mathrm{OR}=0.6,95 \%$ CI $0.37-0.96, p=0.03)$, whereas the same association could not be verified in the ICP group $(p=0.52)$ (Table 7 and Table 8). Using a recessive model (TT genotypes in patients versus controls) a more obvious difference was observed in the ACP 
group $(1.7 \%)$ than in ICP patients $(3.8 \%)$ versus controls $(5.8 \%)$, however, due to the limited sample size it did not reach statistical significance (Table 7 and Table 8).

\begin{tabular}{|c|c|c|c|c|c|c|c|}
\hline CELA3A & Nucleotide Change & Genotype & Patients & Controls & OR & $p$ Value & $95 \% \mathrm{CI}$ \\
\hline \multirow{3}{*}{ Intron 6} & \multirow{3}{*}{ c. $643-78 \mathrm{~T}>\mathrm{C}$} & $\mathrm{TT}$ & $153 / 225(68 \%)$ & $186 / 295(63 \%)$ & - & - & - \\
\hline & & $\mathrm{TC}$ & $63 / 225(28 \%)$ & $94 / 295(31.9 \%)$ & 0.80 & 0.25 & $0.56-1.16$ \\
\hline & & $\mathrm{CC}$ & $9 / 225(4 \%)$ & $15 / 295(5.1 \%)$ & 0.78 & 0.56 & $0.33-1.81$ \\
\hline \multirow{3}{*}{ Exon 7} & \multirow{3}{*}{ c. $750 \mathrm{C}>\mathrm{T}$} & $\mathrm{CC}$ & $132 / 225(58.7 \%)$ & $\begin{array}{l}158 / 295 \\
(53.5 \%)\end{array}$ & - & - & - \\
\hline & & $\mathrm{CT}$ & $81 / 225(36 \%)$ & $\begin{array}{l}117 / 295 \\
(39.7 \%)\end{array}$ & 0.81 & 0.25 & $0.57-1.15$ \\
\hline & & TT & $12 / 225(5.3 \%)$ & $20 / 295(6.8 \%)$ & 0.77 & 0.5 & $0.37-1.62$ \\
\hline \multirow{3}{*}{ Exon 7} & \multirow{3}{*}{ c. $753 \mathrm{G}>\mathrm{A}$} & GG & $132 / 225(58.7 \%)$ & $\begin{array}{l}158 / 295 \\
(53.5 \%)\end{array}$ & - & - & - \\
\hline & & GA & $81 / 225(36 \%)$ & $\begin{array}{l}117 / 295 \\
(39.7 \%)\end{array}$ & 0.81 & 0.25 & $0.57-1.15$ \\
\hline & & $\mathrm{AA}$ & $12 / 225(5.3 \%)$ & $20 / 295(6.8 \%)$ & 0.77 & 0.5 & $0.37-1.62$ \\
\hline \multirow{3}{*}{ Intron 7} & \multirow{3}{*}{ c. $795+21 \mathrm{C}>\mathrm{A}$} & $\mathrm{CC}$ & $17 / 225(7.6 \%)$ & $32 / 295(10.8 \%)$ & - & - & - \\
\hline & & $\mathrm{CA}$ & $95 / 225(42.2 \%)$ & $\begin{array}{l}127 / 295 \\
(43.1 \%)\end{array}$ & 1.49 & 0.21 & $0.80-2.76$ \\
\hline & & AA & $113 / 225(50.2 \%)$ & $\begin{array}{l}136 / 295 \\
(46.1 \%)\end{array}$ & 1.18 & 0.35 & $0.83-1.67$ \\
\hline CELA3B & Nucleotide Change & Genotype & Patients & Controls & OR & $p$ Value & $95 \% \mathrm{CI}$ \\
\hline \multirow{3}{*}{ Intron 6} & \multirow{3}{*}{ c. $643-7 \mathrm{G}>\mathrm{T}$} & GG & $159 / 225(70.6 \%)$ & $\begin{array}{l}185 / 293 \\
(63.1 \%)\end{array}$ & - & - & - \\
\hline & & GT & $60 / 225(26.7 \%)$ & $91 / 293(31.1 \%)$ & 0.71 & 0.07 & $0.49-1.03$ \\
\hline & & TT & $6 / 225(2.7 \%)$ & $17 / 293(5.8 \%)$ & 0.44 & 0.09 & $0.17-1.15$ \\
\hline \multirow{3}{*}{ Exon 7} & \multirow{3}{*}{ c. $780 \mathrm{~T}>\mathrm{C}$} & $\mathrm{TT}$ & $1 / 225(0.5 \%)$ & $0 / 293(0 \%)$ & - & - & - \\
\hline & & $\mathrm{TC}$ & $3 / 225(1.3 \%)$ & $6 / 293(2 \%)$ & - & - & - \\
\hline & & $\mathrm{CC}$ & $221 / 225(98.2 \%)$ & $287 / 293(98 \%)$ & 1.15 & 0.83 & $0.32-4.14$ \\
\hline \multirow{3}{*}{ Intron 7} & \multirow{3}{*}{ c. $795+21 \mathrm{C}>\mathrm{A}$} & $\mathrm{CC}$ & $10 / 225(4.4 \%)$ & $24 / 293(8.2 \%)$ & - & - & - \\
\hline & & $\mathrm{CA}$ & $90 / 225(40 \%)$ & $\begin{array}{l}125 / 293 \\
(42.7 \%)\end{array}$ & 1.92 & 0.09 & $0.90-4.1$ \\
\hline & & AA & $125 / 225(55.6 \%)$ & $\begin{array}{l}144 / 293 \\
(49.1 \%)\end{array}$ & 1.29 & 0.15 & $0.91-1.8$ \\
\hline
\end{tabular}

Table 6. Genotype distribution of common CELA3A and CELA3B variants. Results were analyzed assuming dominant (shown in italics) or recessive models of inheritance. OR, odds ratio; $C I$, confidence interval.

\begin{tabular}{cccccccc}
\hline CELA3A & $\begin{array}{c}\text { Nucleotide } \\
\text { Change }\end{array}$ & Genotype & ACP Patients & Controls & OR & $\boldsymbol{p}$ Value & 95\% CI \\
\hline \multirow{3}{*}{ Intron 6 } & & TT & $83 / 120(69.2 \%)$ & $186 / 295(63 \%)$ & - & - & - \\
& \multirow{2}{*}{ c.643-78T>C } & TC & $31 / 120(25.8 \%)$ & $94 / 295(31.9 \%)$ & 0.76 & 0.24 & $0.48-1.2$ \\
& & CC & $6 / 120(5 \%)$ & $15 / 295(5.1 \%)$ & 0.98 & 0.97 & $0.37-2.6$ \\
\hline
\end{tabular}




\begin{tabular}{|c|c|c|c|c|c|c|c|}
\hline \multirow{3}{*}{ Exon 7} & \multirow{3}{*}{ c. $750 \mathrm{C}>\mathrm{T}$} & $\mathrm{CC}$ & $70 / 120(58.3 \%)$ & $158 / 295(53.5 \%)$ & - & - & - \\
\hline & & $\mathrm{CT}$ & $43 / 120(35.8 \%)$ & $117 / 295(39.7 \%)$ & 0.82 & 0.38 & $0.54-1.27$ \\
\hline & & TT & $7 / 120(5.9 \%)$ & $20 / 295(6.8 \%)$ & 0.85 & 0.72 & $0.35-2.07$ \\
\hline \multirow{3}{*}{ Exon 7} & \multirow{3}{*}{ c. $753 \mathrm{G}>\mathrm{A}$} & GG & $70 / 120(58.3 \%)$ & $158 / 295(53.5 \%)$ & - & - & - \\
\hline & & GA & $43 / 120(35.8 \%)$ & $117 / 295(39.7 \%)$ & 0.82 & 0.38 & $0.54-1.27$ \\
\hline & & AA & $7 / 120(5.9 \%)$ & $20 / 295(6.8 \%)$ & 0.85 & 0.72 & $0.35-2.07$ \\
\hline \multirow{3}{*}{ Intron 7} & \multirow{3}{*}{ c. $795+21 \mathrm{C}>\mathrm{A}$} & $\mathrm{CC}$ & $10 / 120(8.3 \%)$ & $32 / 295(10.8 \%)$ & - & - & - \\
\hline & & $\mathrm{CA}$ & $53 / 120(44.2 \%)$ & $127 / 295(43.1 \%)$ & 1.34 & 0.44 & $0.64-2.82$ \\
\hline & & $\mathrm{AA}$ & $57 / 120(47.5 \%)$ & $136 / 295(46.1 \%)$ & 1.06 & 0.8 & $0.69-1.62$ \\
\hline CELA3B & $\begin{array}{c}\text { Nucleotide } \\
\text { Change }\end{array}$ & Genotype & ACP Patients & Controls & OR & $p$ Value & $95 \% \mathrm{CI}$ \\
\hline \multirow{3}{*}{ Intron 6} & \multirow{3}{*}{ c. $643-7 \mathrm{G}>\mathrm{T}$} & GG & $89 / 120(74.1 \%)$ & $185 / 293(63.1 \%)$ & - & - & - \\
\hline & & GT & $29 / 120(24.2 \%)$ & $91 / 293(31.1 \%)$ & 0.6 & $0.03 *$ & $0.37-0.96$ \\
\hline & & TT & $2 / 120(1.7 \%)$ & $17 / 293(5.8 \%)$ & 0.28 & 0.09 & $0.06-1.21$ \\
\hline \multirow{3}{*}{ Exon 7} & \multirow{3}{*}{ c. $780 \mathrm{~T}>\mathrm{C}$} & TT & $1 / 120(0.8 \%)$ & $0 / 293(0 \%)$ & - & - & - \\
\hline & & $\mathrm{TC}$ & $1 / 120(0.8 \%)$ & $6 / 293(2 \%)$ & - & - & - \\
\hline & & $\mathrm{CC}$ & $118 / 120(98.4 \%)$ & $287 / 293(98 \%)$ & 1.23 & 0.8 & $0.25-6.2$ \\
\hline \multirow{3}{*}{ Intron 7} & \multirow{3}{*}{ c. $795+21 \mathrm{C}>\mathrm{A}$} & $\mathrm{CC}$ & $7 / 120(5.8 \%)$ & $24 / 293(8.2 \%)$ & - & - & - \\
\hline & & $\mathrm{CA}$ & $47 / 120(39.2 \%)$ & $125 / 293(42.7 \%)$ & 1.44 & 0.41 & $0.60-3.44$ \\
\hline & & AA & $66 / 120(55 \%)$ & $144 / 293(49.1 \%)$ & 1.27 & 0.28 & $0.83-1.94$ \\
\hline
\end{tabular}

Table 7. Genotype distribution of common CELA3A and CELA3B variants in patients with alcoholic chronic pancreatitis (ACP) and controls without pancreatic disease. Results were analyzed assuming dominant (shown in italics) or recessive models of inheritance. OR, odds ratio; CI, confidence interval. Asterisk indicates significant association.

\begin{tabular}{|c|c|c|c|c|c|c|c|}
\hline CELA3A & Nucleotide Change & Genotype & ICP Patients & Controls & OR & $p$ Value & 95\% CI \\
\hline \multirow{3}{*}{ Intron 6} & \multirow{3}{*}{ c. $643-78 \mathrm{~T}>\mathrm{C}$} & $\mathrm{TT}$ & $70 / 105(66.6 \%)$ & $186 / 295(63 \%)$ & - & - & - \\
\hline & & $\mathrm{TC}$ & $32 / 105(30.5 \%)$ & $94 / 295(31.9 \%)$ & 0.85 & 0.51 & $0.53-1.36$ \\
\hline & & $\mathrm{CC}$ & $3 / 105(2.9 \%)$ & $15 / 295(5.1 \%)$ & 0.55 & 0.35 & $0.16-1.94$ \\
\hline \multirow{3}{*}{ Exon 7} & \multirow{3}{*}{ c. $750 \mathrm{C}>\mathrm{T}$} & $\mathrm{CC}$ & $62 / 105(59 \%)$ & $158 / 295(53.5 \%)$ & - & - & - \\
\hline & & $\mathrm{CT}$ & $38 / 105(36.2 \%)$ & $117 / 295(39.7 \%)$ & 0.8 & 0.33 & $0.51-1.26$ \\
\hline & & TT & $5 / 105(4.8 \%)$ & $20 / 295(6.8 \%)$ & 0.69 & 0.47 & $0.25-1.88$ \\
\hline \multirow{3}{*}{ Exon 7} & \multirow{3}{*}{ c. $753 \mathrm{G}>\mathrm{A}$} & GG & $62 / 105(59 \%)$ & $158 / 295(53.5 \%)$ & - & - & - \\
\hline & & GA & $38 / 105(36.2 \%)$ & $117 / 295(39.7 \%)$ & 0.8 & 0.33 & $0.51-1.26$ \\
\hline & & $\mathrm{AA}$ & $5 / 105(4.8 \%)$ & $20 / 295(6.8 \%)$ & 0.69 & 0.47 & $0.25-1.88$ \\
\hline \multirow{3}{*}{ Intron 7} & \multirow{3}{*}{ c. $795+21 \mathrm{C}>\mathrm{A}$} & $\mathrm{CC}$ & $7 / 105(6.7 \%)$ & $32 / 295(10.8 \%)$ & - & - & - \\
\hline & & $\mathrm{CA}$ & $42 / 105(40 \%)$ & $127 / 295(43.1 \%)$ & 1.7 & 0.22 & $0.73-3.99$ \\
\hline & & $\mathrm{AA}$ & $56 / 105(53.3 \%)$ & $136 / 295(46.1 \%)$ & 1.34 & 0.2 & $0.85-2.09$ \\
\hline CELA3B & Nucleotide Change & Genotype & ICP Patients & Controls & OR & $p$ Value & $95 \% \mathrm{CI}$ \\
\hline \multirow{3}{*}{ Intron 6} & \multirow{3}{*}{ c. $643-7 \mathrm{G}>\mathrm{T}$} & GG & $70 / 105(66.7 \%)$ & $185 / 293(63.1 \%)$ & - & - & - \\
\hline & & GT & $31 / 105(29.5 \%)$ & $91 / 293(31.1 \%)$ & 0.86 & 0.52 & $0.54-1.37$ \\
\hline & & $\mathrm{TT}$ & $4 / 105(3.8 \%)$ & $17 / 293(5.8 \%)$ & 0.64 & 0.44 & $0.21-1.96$ \\
\hline \multirow{2}{*}{ Exon 7} & \multirow{2}{*}{ c. $780 \mathrm{~T}>\mathrm{C}$} & TT & 0/105 (0\%) & 0/293 (0\%) & - & - & - \\
\hline & & $\mathrm{TC}$ & $2 / 105(1.9 \%)$ & $6 / 293(2 \%)$ & - & - & - \\
\hline
\end{tabular}




\begin{tabular}{|c|c|c|c|c|c|c|c|}
\hline & & $\mathrm{CC}$ & $103 / 105(98.1 \%)$ & $287 / 293(98 \%)$ & 1.08 & 0.93 & $0.21-5.42$ \\
\hline \multirow{3}{*}{ Intron 7} & \multirow{3}{*}{ c. $795+21 \mathrm{C}>\mathrm{A}$} & $\mathrm{CC}$ & $3 / 105(2.8 \%)$ & $24 / 293(8.2 \%)$ & - & - & - \\
\hline & & $\mathrm{CA}$ & $43 / 105(41 \%)$ & $125 / 293(42.7 \%)$ & 3.03 & 0.08 & $0.89-10.29$ \\
\hline & & $\mathrm{AA}$ & $59 / 105(56.2 \%)$ & $144 / 293(49.1 \%)$ & 1.33 & 0.22 & $0.85-2.08$ \\
\hline
\end{tabular}

Table 8. Genotype distribution of common CELA3A and CELA3B variants in patients with idiopathic chronic pancreatitis (ICP). Results were analyzed assuming dominant (shown in italics) or recessive models of inheritance. OR, odds ratio; $C I$, confidence interval.

In summary, with the exception of the apparently protective c.643$7 \mathrm{G}>\mathrm{T} C E L A 3 B$ variant, we found no other association of CELA3A and CELA3B variants with $\mathrm{CP}$ or disease subgroups ACP and ICP. Importantly, the lack of association between variants at amino-acid position 241 and CP indicates that changes in complex formation between proelastases and procarboxypeptidases have no appreciable effect on the risk of CP.

\subsubsection{Functional Analysis of Missense Variants and the Gene Conversion Event}

To characterize how missense mutations in CELA3A and CELA3B and the gene conversion in CELA3B alter elastase secretion and activity, we transfected human embryonic kidney (HEK) 293T cells with expression plasmids and measured proelastase levels in the conditioned medium by sodium dodecyl sulfate-polyacrylamide gel electrophoresis (SDSPAGE) and elastase activity by enzymatic assays. When elastase secretion into the medium was determined at $48 \mathrm{~h}$ after transfection, all variants were secreted normally, as judged by Coomassie Blue staining and densitometry of stained gels (Figure 9). CELA3B variant p.V232L exhibited a slight $(\sim 20 \%)$ but reproducible increase in secretion. Similarly, elastase activity of the conditioned medium after activation with trypsin showed no major differences among the variants and wild-type enzymes when measured with the Suc-Ala-Ala-Pro-Ala- $p$ nitroanilide chromogenic peptide substrate (Figure 10). Consistent with its increased levels of secretion, variant p.V232L exhibited higher activity while the activity of the gene conversion variant (p.T246F, p.R247I, p.R248W) was slightly (1.4-fold) reduced relative to wild-type CELA3B. Interestingly, variants p.G241A in CELA3A and p.A241G in CELA3B had opposite effects on elastase activity. Thus, activity of the CELA3A p.G241A variant was increased by 1.8 -fold, whereas activity of the CELA3B p.A241G variant was decreased by 2.2-fold relative to their respective wild-type controls. Even though these changes in activity controlled by the amino acid at position 241 (Gly versus Ala) are intriguing mechanistically, they have no impact on CP risk as demonstrated by the lack of genetic association described above. 


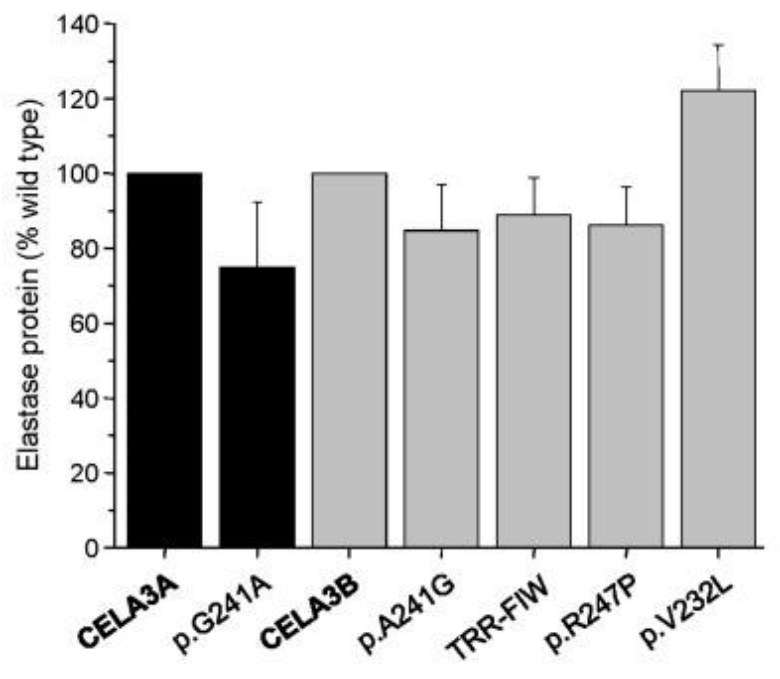

(A)
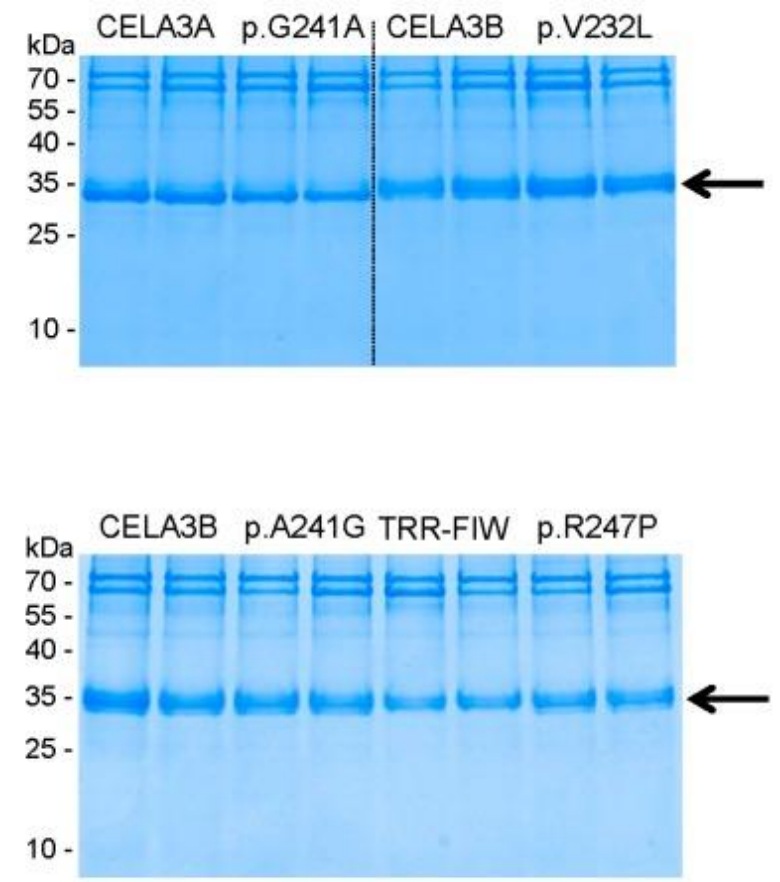

(B)

Figure 9 Secretion of CELA3A and CELA3B variants. Human embryonic kidney (HEK) $293 T$ cells were transfected with the indicated constructs and conditioned medium was collected 48 $h$ after transfection. Levels of secreted proelastases were determined by sodium dodecyl sulfate-polyacrylamide gel electrophoresis (SDS-PAGE) and Coomassie Blue staining as described in Materials and Methods. (A) Densitometric quantitation of secreted CELA3A and CELA3B. Average values from three transfections with standard deviation (S.D.) are indicated; expressed as percent of wild-type levels; (B) Representative gels are shown with samples loaded in duplicate. The molecular mass markers were PageRuler Prestained Protein Ladder (Thermo Scientific, Waltham, MA, USA; PI-26616). The arrow indicates the proelastase bands. The diffuse appearance of the CELA3B bands is likely due to $\mathrm{N}$ glycosylation. TRR-FIW designates the p.T246F, p.R247I, p.R248W variant which is the product of the gene conversion. 


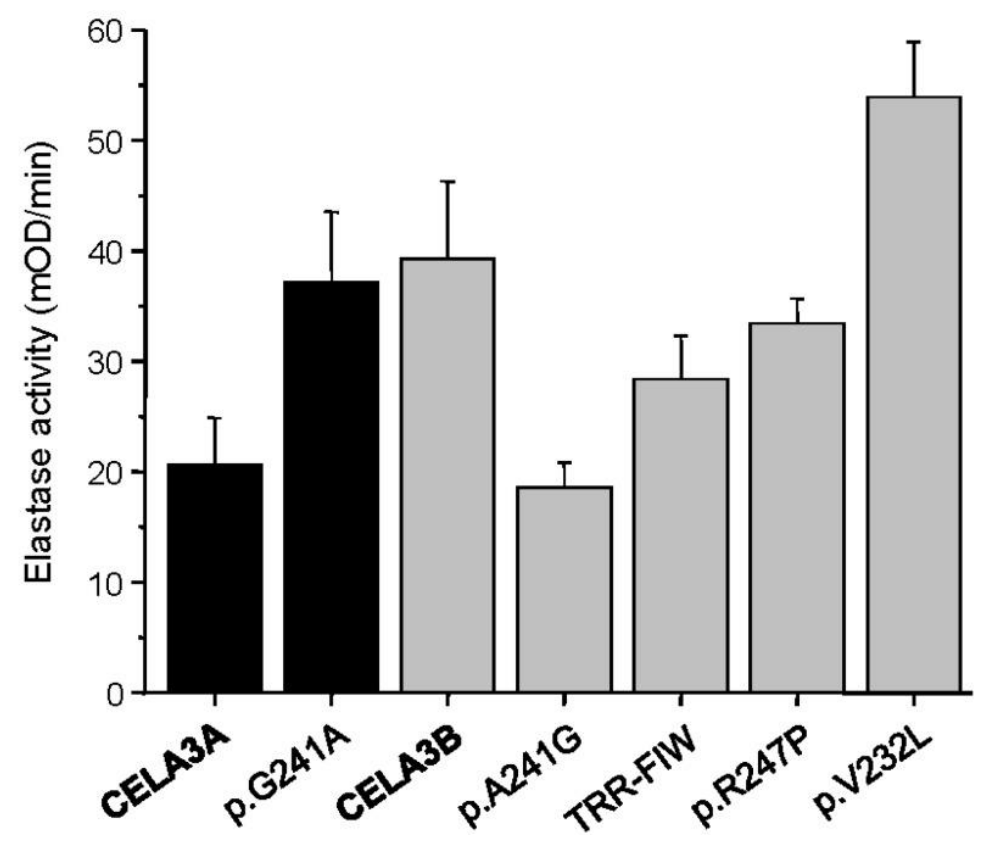

Figure 10. Activity of CELA3A and CELA3B variants in the conditioned medium of transfected HEK $293 T$ cells. Proelastases were activated with trypsin and elastase activity was determined as described in Materials and Methods. Average values \pm S.D. from three transfections are shown. TRR-FIW designates the p.T246F, p.R247I, p.R248W variant which is the product of the gene conversion. 


\section{DISCUSSION}

\subsection{ScheBo Pancreatic Elastase 1 Test}

In this study, we evaluated the isoform specificity of the ScheBo Pancreatic Elastase 1 Stool Test. The clinical utility of the fecal elastase test in the evaluation of pancreatic insufficiency has been well established and it has become widely used for routine indirect testing of pancreatic function(Amann, Bishop, Curington, \& Toskes, 1996; DomínguezMuñoz, D. Hardt, Lerch, \& Löhr, 2017; Dominici \& Franzini, 2002; Hahn et al., 2005; Hardt et al., 2003; Keim, Teich, \& Moessner, 2003; Leeds, Oppong, \& Sanders, 2011; Loser, Mollgaard, \& Folsch, 1996; Lüth et al., 2001; Miendje et al., 2004; Schneider, Funk, Caspary, \& Stein, 2005; Stein et al., 1996; Weiss, Budde, \& Lerch, 2016). Although limitations were also indicated by some studies (Amann et al., 1996; Lüth et al., 2001), the test gained popularity because it is non-invasive, relatively rapid, unaffected by pancreatic enzyme replacement therapy and clearly superior to the previously used indirect test that measured fecal chymotrypsin activity. Somewhat surprisingly, the exact molecular targets of this ELISA assay have not been characterized; it has been unclear which elastase isoform(s) the test detects, and whether other homologous pancreatic proteinases interfere with the assay. The misnomer used in the test's commercial name adds to the uncertainty as to what exactly it measures. As discussed in the introduction of this paper, CELA1 is not expressed in the human pancreas and the test's name in all likelihood refers to one of the several historic names used for CELA3B in the article published by Largman et al. in 1976. Thus, we expected the test would detect CELA3B; yet the vexing questions remained whether the 92\% identical CELA3A isoform was equally well detected and whether natural genetic variants of CELA3A and CELA3B affected test performance. Taking advantage of developments in the genomic sequencing and annotation of human digestive enzymes, we used well-defined recombinant preparations of human elastases, chymotrypsins and trypsins to characterize the specificity of the ScheBo test.

Our findings confirmed that the primary target of the test is CELA3B, however, CELA3A is also detected, approximately 4-fold weaker than CELA3B. Importantly, CELA2A, chymotrypsins CTRB1, CTRB2, CTRC, CTRL1 and trypsins PRSS1, PRSS2, PRSS3 produced minimal or no signal in this ELISA assay. Elastases are secreted as inactive precursors (zymogens) by the pancreas and these proelastases become activated in the 
duodenum by trypsin. Proelastases can also suffer autolysis due to their intrinsic zymogen activity or by active elastases (Szabó et al., 2016). The most prominent autolytic cleavage takes place at the Val30-Asn31 peptide bond in CELA3B (and to a lesser extent at the Val30His31 peptide bond in CELA3A) resulting in a catalytically inactive elastase species (GomisRüth et al., 1998; Szabó et al., 2016). We compared test performance on all molecular forms of CELA3B and found no difference in detection efficiency, indicating that test results are unaffected by the activation state or the degree of autolysis of secreted elastases.

Another potentially confounding factor is the occurrence of natural genetic variants of the CELA3 isoforms that might react differently with the ELISA assay than the wild-type targets. The test is based on the binding of elastase to two monoclonal antibodies (see Figure 1) and genetic variants can alter the surface epitopes where these antibodies bind, resulting in altered detection efficiency. We characterized the effect on test performance of all genetic variants of CELA3A and CELA3B, which occur at or above $1 \%$ frequency in the population and found no clinically meaningful changes. Only one variant, CELA3B W79R, exhibited increased detection by approximately 1.4-fold, which should be inconsequential in heterozygous carriers. Our studies do not rule out the possibility that rare or private genetic variants in certain patients may interfere with the test, however, for the large majority of the population the ScheBo test should not be affected by common genetic variants in the CELA3 isoforms.

We performed limited epitope mapping to identify amino-acids that are responsible for the preferential detection of CELA3B over CELA3A by the ScheBo test. We identified Glu154 in CELA3B, which is Lys in CELA3A, as a key determinant of recognition by the capturing monoclonal antibody. Mutation E154K in CELA3B abolished detection by the ELISA assay. Surprisingly, however, the opposite mutation K154E in CELA3A did not improve detection by the test and simultaneous mutation of the nearby Arg179 to Leu (R179L) was required to achieve signal levels that were comparable to those of CELA3B.

Position 154 is located within a potential N-glycosylation site and we considered the possibility that the side-chain of amino-acid 154 may alter glycosylation and thereby affect antibody recognition. N-linked glycosylation occurs on Asn residues in Asn-Xaa-Ser/Thr sequons where Xaa can be any amino acid except for Pro. Importantly, however, if the amino acid following the sequon is a Pro, $\mathrm{N}$-glycosylation is inhibited. In CELA3A the sequon Asn153-Lys154-Thr155 and in CELA3B the sequon Asn153-Glu154-Thr155 are followed by 
Pro156, indicating that Asn153 is unlikely to undergo glycosylation in either isoform. This notion is consistent with earlier studies which characterized the glycosylation of CELA3B and found a single N-glycosylation site at Asn114. Finally, although data are not shown, we observed no change in the detection of CELA3A and CELA3B by the ScheBo test after treatment with peptide-N-glycosidase F (PNGase F).

In conclusion, we characterized the molecular targets of the ScheBo Pancreatic Elastase 1 Stool Test and demonstrated that it predominantly measures CELA3B but also detects CELA3A with lower efficacy. Other pancreatic proteinases or genetic variants of the CELA3 isoforms have no appreciable impact on test performance.

\subsection{Genetic analysis study}

In the present study we tested the hypothesis that changes in complex formation between human proelastases and procarboxypeptidases might alter risk for $\mathrm{CP}$. We speculated that individual variations in the levels of these zymogen complexes may influence digestive enzyme activation as the free, uncomplexed enzyme should be more susceptible to activation than its complexed form. Indeed, we recently demonstrated that activation of human procarboxypeptidases A1 and A2 were delayed when bound to human proCELA3B. Although activation of proCELA3B did not seem to be directly affected by complex formation, changes in folding, solubility, packaging and secretion might be altered which can ultimately promote ectopic elastase activation inside the pancreas. To identify whether such mechanisms play a role in $\mathrm{CP}$ risk, we took advantage of the observation that the primary amino-acid determinants of complex formation in CELA3A and CELA3B are polymorphic in the population. Thus, normally proCELA3A binds poorly to procarboxypeptidases due to the presence of Gly241, whereas proCELA3B which contains Ala241 forms tight complexes (Szabó et al., 2016). Individuals carrying a heterozygous p.G241A mutation in CELA3A should have increased complex levels in their pancreatic secretions. Conversely, subjects with the p.A241G variant in CELA3B should exhibit decreased complex formation and higher levels of free zymogens. Should CP risk be elevated by decreased complex formation, one would expect to observe underrepresentation of the CELA3A p.G241A variant and/or enrichment of the CELA3B p.A241G variant in a cohort of CP patients versus population controls. 
To determine allele frequencies of these variants, we sequenced exon 7 and flanking intronic regions of CELA3A and CELA3B in $\mathrm{CP}$ patients and controls of Hungarian origin. We found that allele frequencies of CELA3A p.G241A and CELA3B p.A241G were not significantly different between the two groups, indicating that these variants do not alter $\mathrm{CP}$ risk. Despite the lack of statistical significance, an opposing trend for enrichment of the two variants was apparent. Thus, CELA3A variant p.G241A was slightly overrepresented in controls while CELA3B variant p.A241G was overrepresented in patients. Assuming the OR values represent the true effect sizes, we would need a much larger cohort to confirm these findings with statistical significance. These effects, on the other hand, would be still clinically insignificant, which does not justify further extension of the studies.

In addition to the position 241 variants discussed above, we identified six synonymous variants, two missense variants, a gene conversion event and ten variants in the flanking intronic regions. Intriguingly, CELA3B variant c.643-7G>T in intron 6 was significantly underrepresented in ACP patients, indicating an approximately 1.7-fold protective effect against CP. This variant is located relatively close to the pre-mRNA splice site and it is conceivable that it might disrupt splicing and decrease CELA3B expression. This finding suggests that elastase activity contributes to pancreatitis risk and warrants extension of sequence analysis of the CELA3A and CELA3B genes and replication of the observed association(s) in an independent cohort. None of the other variants showed a significant difference in frequency between CP patients and controls. Finally, we performed functional analysis on all missense variants detected in this study and found no major defects in proelastase secretion or elastase activity.

We discovered a rare gene conversion event between exons 7 of CELA3A and CELA3B in an individual with ICP. Gene conversion is a non-reciprocal exchange of genetic information between homologous DNA sequences, most likely as a result of mismatch repair following a heteroduplex formation between the donor and acceptor genes (J. M. Chen, Cooper, Chuzhanova, Ferec, \& Patrinos, 2007). DNA exchange by gene conversion is of paramount importance for the evolution of gene families but it can also cause human diseases (J. M. Chen et al., 2007) including CP and other pancreatic pathologies. Gene conversion events between PRSS1 and PRSS2 or between PRSS1 and the pseudogene PRSS3P2 were shown to generate pathogenic alleles that cause hereditary pancreatitis (Masson, Le Maréchal, Delcenserie, Chen, \& Férec, 2008; Rygiel et al., 2015; Teich et al., 2005) More recently, a 
recombination allele of the carboxyl ester lipase gene (CEL) and its pseudogene CELP was described as a novel genetic risk factor for CP (Fjeld et al., 2015). Finally, conversion events between the SBDS gene and its paralogous duplicated pseudogene SBDSP cause Shwachman-Bodian-Diamond syndrome, an autosomal recessive disorder with pancreatic exocrine insufficiency, hematologic dysfunction, and skeletal abnormalities (Boocock et al., 2003). The newly found gene conversion event between CELA3A and CELA3B was detected in a CP patient, however, this is likely an accidental finding as we found no functional defect with respect to secretion or activity of the converted CELA3B that might suggest a pathogenic role in $\mathrm{CP}$.

In conclusion, our study demonstrated that variants affecting amino-acid position 241 in human CELA3A and CELA3B are not associated with CP, indicating that changes in complex formation between human proelastases and procarboxypeptidases do not influence the risk for $\mathrm{CP}$. The observation that intronic variant $\mathrm{c.643-7G}>\mathrm{T}$ in CELA3B was significantly underrepresented in ACP patients suggests this might be a protective variant. 


\section{Summary and future plans}

In this work we investigated to clarify the role of pancreatic elastases in the exocrine pancreatic diseases from molecular mechanism to the bedside.

Performing a genetic association study in order to further understand a possible patomechanism of the chronic pancreatitis we demonstrated that variants affecting amino-acid position 241 in human CELA3A and CELA3B are not associated with CP, indicating that changes in complex formation between human proelastases and procarboxypeptidases do not influence the risk for CP. We observed that intronic variant c.643-7G>T in CELA3B was significantly underrepresented in ACP patients suggests this might be a protective variant.

Determination of fecal elastases by ELISA method is a non-invasive, simple, and reliable clinical test but the exact molecular target of it remained unclear. In our study we characterized isoform specificity of the Schebo Pancreatic Elastase 1 Stool test, we demonstrated that the test predominantly measures CELA3B but also detects CELA3A with lower efficacy. Other pancreatic proteinases or genetic variants of the CELA3 isoforms have no appreciable effect on test performance indicating that these variants have no impact on the result of the clinical test. Sziegoleit (1984) measured CELA3B levels as 4-6\% of total juice protein (Andreas Sziegoleit, 1984) and other studies indicated that mRNA and protein levels for the two CELA3 isoforms are grossly comparable (Shirasu et al., 1988; Tani et al., 1988). However, there is no information available on how the expression of CELA3A and CELA3B in the pancreas might vary under different physiological and pathological conditions. It is intriguing to speculate that test performance might be affected by changes in the CELA3 isoform ratio. For this reason, development of a test that specifically detects CELA3B without any cross-reactivity with CELA3A could potentially offer a better diagnostic tool. 


\section{References}

Amann, S. T., Bishop, M., Curington, C., \& Toskes, P. P. (1996). Fecal pancreatic elastase 1 is inaccurate in the diagnosis of chronic pancreatitis. Pancreas, 13(3), 226-230. https://doi.org/10.1097/00006676-199610000-00002

Baló, J., \& Banga, I. (1949). Elastase and elastase-inhibitor. Nature, 164, 491.

Baló, J., \& Banga, I. (1950). The elastolytic activity of pancreatic extracts. Biochem J, (46), 384-387.

Boocock, G. R. B., Morrison, J. A., Popovic, M., Richards, N., Ellis, L., Durie, P. R., \& Rommens, J. M. (2003). Mutations in SBDS are associated with Shwachman-Diamond syndrome. Nature Genetics, 33(1), 97-101. https://doi.org/10.1038/ng1062

Boros, E., Szabó, A., Zboray, K., Héja, D., Pál, G., \& Sahin-Tóth, M. (2017). Overlapping specificity of duplicated human pancreatic elastase 3 isoforms and archetypal porcine elastase 1provides clues to evolution of digestive enzymes. Journal of Biological Chemistry, 292(7), 2690-2702. https://doi.org/10.1074/jbc.M116.770560

Chen, J.-M., \& Ferec, C. (2009). Chronic pancreatitis: genetics and pathogenesis. Annual Review of Genomics and Human Genetics, 10, 63-87. https://doi.org/10.1146/annurevgenom-082908-150009

Chen, J. M., Cooper, D. N., Chuzhanova, N., Ferec, C., \& Patrinos, G. P. (2007). Gene conversion: mechanisms, evolution and human disease. Nat Rev Genet. https://doi.org/nrg2193 [pii]ไr10.1038/nrg2193

Domínguez-Muñoz, J. E., D. Hardt, P., Lerch, M. M., \& Löhr, M. J. (2017). Potential for Screening for Pancreatic Exocrine Insufficiency Using the Fecal Elastase-1 Test. Digestive Diseases and Sciences. https://doi.org/10.1007/s10620-017-4524-z

Dominici, R., \& Franzini, C. (2002). Fecal elastase-1 as a test for pancreatic function: a review. Clinical Chemistry and Laboratory Medicine : CCLM / FESCC, 40(4), 325-332. https://doi.org/10.1515/CCLM.2002.051 
Fjeld, K., Weiss, F. U., Lasher, D., Rosendahl, J., Chen, J. M., Johansson, B. B., ... Molven, A. (2015). A recombined allele of the lipase gene CEL and its pseudogene CELP confers susceptibility to chronic pancreatitis. Nature Genetics, 47(5), 518-522. https://doi.org/10.1038/ng.3249

Gertler, A. (1971). The Non-Specific Electrostatic Nature of the Adsorption of Elastase and Other Basic Proteins on Elastin. European Journal of Biochemistry, 20(4), 541-546. https://doi.org/10.1111/j.1432-1033.1971.tb01425.x

Gertler, A., Weiss, Y., \& Burstein, Y. (1977). Purification and Characterization of Porcine Elastase II and Investigation of Its Elastolytic Specificity. Biochemistry, 16(12), 27092716. https://doi.org/10.1021/bi00631a019

Gomis-Rüth, F. X., Gómez-Ortiz, M., Vendrell, J., Ventura, S., Bode, W., Huber, R., \& Avilés, F. X. (1998). Cutting at the right place - The importance of selective limited proteolysis in the activation of proproteinase E. European Journal of Biochemistry, 251(3), 839-844. https://doi.org/10.1046/j.1432-1327.1998.2510839.x

Hahn, J. U., Bochnig, S., Kerner, W., Koenig, H., Sporleder, B., Lankisch, P. G., ... Lowenfels, A. B. (2005). A new fecal elastase 1 test using polyclonal antibodies for the detection of exocrine pancreatic insufficiency [1]. Pancreas. https://doi.org/10.1097/01.mpa.0000153617.40513.34

Hardt, P. D., Hauenschild, A., Nalop, J., Marzeion, A. M., Porsch-Özcürümez, M., Luley, C., ... Kloer, H. U. (2003). The commercially available ELISA for pancreatic elastase 1 based on polyclonal antibodies does measure an as yet unknown antigen different from purified elastase 1. Binding studies and clinical use in patients with exocrine pancreatic insufficiency. Zeitschrift Fur Gastroenterologie, 41(9), 903-906. https://doi.org/10.1055/s-2003-41832

Hegyi, E., Geisz, A., Sahin-Tóth, M., Derikx, M. H. M., Németh, B. C., Balázs, A., .. Czakó, L. (2016). SPINK1 Promoter Variants in Chronic Pancreatitis. Pancreas, 45(1), 148153. https://doi.org/10.1097/MPA.0000000000000412

Kawashima, I., Tani, T., Shimoda, K., \& Takiguchi, Y. O. (1987). Characterization of Pancreatic Elastase II cDNAs: Two Elastase II mRNAs Are Expressed in Human 
Pancreas. DNA, 6(2), 163-172. https://doi.org/10.1089/dna.1987.6.163

Keim, V., Teich, N., \& Moessner, J. (2003). Clinical value of a new fecal elastase test for detection of chronic pancreatitis. Clinical Laboratory, 49(5-6), 209-215.

Kukor, Z., Tóth, M., \& Sahin-Tóth, M. (2003). Human anionic trypsinogen. Properties of autocatalytic activation and degradation and implications in pancreatic diseases. European Journal of Biochemistry, 270(9), 2047-2058. https://doi.org/10.1046/j.14321033.2003.03581.x

Largman, C., Brodrick, J. W., \& Geokas, M. C. (1976). Purification and characterization of two human pancreatic elastases. Biochemistry, 15(11), 2491-2500.

Leeds, J. S., Oppong, K., \& Sanders, D. S. (2011). The role of fecal elastase-1 in detecting exocrine pancreatic disease. Nature Reviews Gastroenterology and Hepatology. https://doi.org/10.1038/nrgastro.2011.91

Loser, C., Mollgaard, A., \& Folsch, U. R. (1996). Faecal elastase 1: a novel, highly sensitive, and specific tubeless pancreatic function test. Gut, 39(4), 580-586. https://doi.org/10.1136/gut.39.4.580

Lüth, S., Teyssen, S., Forssmann, K., Kölbel, C., Krummenauer, F., \& Singer, M. V. (2001). Fecal elastase-1 determination: "Gold standard" of indirect pancreatic function tests? Scandinavian Journal of Gastroenterology, 36(10), 1092-1099. https://doi.org/10.1080/003655201750422729

Mallory, P. A., \& Travis, J. (1975). Human Pancreatic Enzymes. Purification and Characterization of a Nonelastolytic Enzyme, Protease e, Resembling Elastase. Biochemistry, 14(4), 722-730. https://doi.org/10.1021/bi00675a012

Masson, E., Le Maréchal, C., Delcenserie, R., Chen, J. M., \& Férec, C. (2008). Hereditary pancreatitis caused by a double gain-of-function trypsinogen mutation. Human Genetics, 123(5), 521-529. https://doi.org/10.1007/s00439-008-0508-6

Miendje, Y., Maisin, D., Sipewa, M. J., Deprez, P., Buts, J. P., De Nayer, P., \& Philippe, M. (2004). Polyclonal versus monoclonal ELISA for the determination of fecal elastase 1: 
diagnostic value in cystic fibrosis and chronic pancreatic insufficiency. Clinical Laboratory, 50(7-8), 419-424.

Moulard, M., Kerfelec, B., Mallet, B., \& Chapus, C. (1989). Identification of a procarboxypeptidase A-truncated protease E binary complex in human pancreatic juice. FEBS Letters, 250(2), 166-170.

Moulard, M., Michon, T., Kerfelec, B., \& Chapus, C. (1990). Further studies on the human pancreatic binary complexes involving procarboxypeptidase A. FEBS Letters, 261(1), 179-183. https://doi.org/10.1016/0014-5793(90)80665-6

Nemeth, B. C., \& Sahin-Toth, M. (2014). Human cationic trypsinogen (PRSS1) variants and chronic pancreatitis. AJP: Gastrointestinal and Liver Physiology, 306(6), G466-G473. https://doi.org/10.1152/ajpgi.00419.2013

Ohlsson, K., \& Olsson, A. S. (1976). Purification and partial characterization of human pancreatic elastase. Hoppe-Seyler's Zeitschrift Fur Physiologische Chemie, 357(8), $1153-1161$.

Pascual, R., Burgos, F. J., Salva, M., Soriano, F., Mendez, E., \& Aviles, F. X. (1989). Purification and properties of five different forms of human procarboxypeptidases. European Journal of Biochemistry, 179(3), 609-616.

Pfutzer, R. H., Barmada, M. M., Brunskill, A. P., Finch, R., Hart, P. S., Neoptolemos, J., ... Whitcomb, D. C. (2000). SPINK1/PSTI polymorphisms act as disease modifiers in familial and idiopathic chronic pancreatitis. Gastroenterology, 119(3), 615-623.

Rose, S. D., \& MacDonald, R. J. (1997). Evolutionary silencing of the human elastase I gene (ELA1). Human Molecular Genetics, 6(6), 897-903. https://doi.org/10.1093/hmg/6.6.897

Rosendahl, J., Witt, H., Szmola, R., Bhatia, E., Ózsvári, B., Landt, O., ... Sahin-Tóth, M. (2008). Chymotrypsin C (CTRC) variants that diminish activity or secretion are associated with chronic pancreatitis. Nature Genetics, 40(1), 78-82. https://doi.org/10.1038/ng.2007.44 
Rygiel, A. M., Beer, S., Simon, P., Wertheim-Tysarowska, K., Oracz, G., Kucharzik, T., ... Weiss, F. U. (2015). Gene conversion between cationic trypsinogen (PRSS1) and the pseudogene trypsinogen 6 (PRSS3P2) in patients with chronic pancreatitis. Human Mutation, 36(3), 350-356. https://doi.org/10.1002/humu.22747

Sahin-Tóth, M., \& Tóth, M. (2000). Gain-of-function mutations associated with hereditary pancreatitis enhance autoactivation of human cationic trypsinogen. Biochemical and Biophysical Research Communications, 278(2), 286-289. https://doi.org/10.1006/bbrc.2000.3797

Schechter, I., \& Berger, A. (2012). On the size of the active site in proteases. I. Papain. 1967. Biochemical and Biophysical Research Communications, 425(3), 497-502. https://doi.org/10.1016/j.bbrc.2012.08.015

Schneider, A., Funk, B., Caspary, W., \& Stein, J. (2005). Monoclonal versus polyclonal ELISA for assessment of fecal elastase concentration: Pitfalls of a new assay. Clinical Chemistry, 51(6), 1052-1054. https://doi.org/10.1373/clinchem.2004.046888

Shirasu, Y., Takemura, K., Yoshida, H., Sato, Y., Iijima, H., Shimada, Y., ... Ishida, A. (1988). Molecular cloning of complementary DNA encoding one of the human pancreatic protease E isozymes. Journal of Biochemistry, 104(2), 259-264.

Stein, J., Jung, M., Sziegoleit, A., Zeuzem, S., Caspary, W. F., \& Lembcke, B. (1996). Immunoreactive elastase I: Clinical evaluation of a new noninvasive test of pancreatic function. Clinical Chemistry, 42(2), 222-226.

Szabó, A., Pilsak, C., Bence, M., Witt, H., \& Sahin-Tóth, M. (2016). Complex formation of human proelastases with procarboxypeptidases A1 and A2. Journal of Biological Chemistry, 291(34), 17706-17716. https://doi.org/10.1074/jbc.M116.743237

Szabó, A., \& Sahin-Tóth, M. (2012a). Determinants of chymotrypsin C cleavage specificity in the calcium-binding loop of human cationic trypsinogen. FEBS Journal, 279(23), 42834292. https://doi.org/10.1111/febs.12018

Szabó, A., \& Sahin-Tóth, M. (2012b). Increased activation of hereditary pancreatitisassociated human cationic trypsinogen mutants in presence of chymotrypsin C. Journal 
of Biological Chemistry, 287(24), 20701-20710. https://doi.org/10.1074/jbc.M112.360065

Szepessy, E., \& Sahin-Tóth, M. (2006). Inactivity of recombinant ELA2B provides a new example of evolutionary elastase silencing in humans. Pancreatology, 6(1-2), 117-122. https://doi.org/10.1159/000090031

Sziegoleit, A. (1982). Purification and characterization of a cholesterol-binding protein from human pancreas. The Biochemical Journal, 207(3), 573-582.

Sziegoleit, A. (1984). A novel proteinase from human pancreas. Biochem. J, 219, 735-742. https://doi.org/10.1042/bj2190735

Sziegoleit, A., Krause, E., Klör, H. U., Kanacher, L., \& Linder, D. (1989). Elastase 1 and chymotrypsin B in pancreatic juice and feces. Clinical Biochemistry, 22(2), 85-89. https://doi.org/10.1016/S0009-9120(89)80003-7

Szmola, R., Kukor, Z., \& Sahin-Tóth, M. (2003). Human mesotrypsin is a unique digestive protease specialized for the degradation of trypsin inhibitors. Journal of Biological Chemistry, 278(49), 48580-48589. https://doi.org/10.1074/jbc.M310301200

Tani, T., Kawashima, I., Furukawa, H., Ohmine, T., \& Takiguchi, Y. (1987). Characterization of a silent gene for human pancreatic elastase I: structure of the 5'-flanking region. Journal of Biochemistry, 101(3), 591-599.

Tani, T., Ohsumi, J., Mita, K., \& Takiguchi, Y. (1988). Identification of a novel class of elastase isozyme, human pancreatic elastase III, by cDNA and genomic gene cloning. Journal of Biological Chemistry, 263(3), 1231-1239.

Teich, N., Nemoda, Z., Köhler, H., Heinritz, W., Mössner, J., Keim, V., \& Sahin-Tóth, M. (2005). Gene conversion between functional trypsinogen genes PRSS1 and PRSS2 associated with chronic pancreatitis in a six-year-old girl. Human Mutation, 25(4), 343347. https://doi.org/10.1002/humu.20148

Weiss, F. U., Budde, C., \& Lerch, M. M. (2016). Specificity of a polyclonal fecal elastase ELISA for CELA3. PLoS ONE, 11(7). https://doi.org/10.1371/journal.pone.0159363 
Whitcomb, D. C., Gorry, M. C., Preston, R. A., Furey, W., Sossenheimer, M. J., Ulrich, C. D., ... Ehrlich, G. D. (1996). Hereditary pancreatitis is caused by a mutation in the cationic trypsinogen gene. Nature Genetics, 14(2), 141-145. https://doi.org/10.1038/ng1096-141

Witt, H., Apte, M. V., Keim, V., \& Wilson, J. S. (2007). Chronic Pancreatitis: Challenges and Advances in Pathogenesis, Genetics, Diagnosis, and Therapy. Gastroenterology, 132(4), 1557-1573. https://doi.org/10.1053/j.gastro.2007.03.001

Witt, H., Beer, S., Rosendahl, J., Chen, J.-M., Chandak, G. R., Masamune, A., ... Sahin-Tóth, M. (2013). Variants in CPA1 are strongly associated with early onset chronic pancreatitis. Nature Genetics, 45(10), 1216-1220. https://doi.org/10.1038/ng.2730

Witt, H., Luck, W., Hennies, H. C., Classen, M., Kage, a, Lass, U., ... Becker, M. (2000). Mutations in the gene encoding the serine protease inhibitor, Kazal type 1 are associated with chronic pancreatitis. Nature Genetics, 25(2), 213-216. https://doi.org/10.1038/76088

Yadav, D., \& Lowenfels, A. B. (2013). The epidemiology of pancreatitis and pancreatic cancer. Gastroenterology. https://doi.org/10.1053/j.gastro.2013.01.068 


\section{Acknowledgements}

First, I would like to express my deepest and sincere gratitude to my mentors Professor Péter Hegyi at the First Department of Internal Medicine, University of Szeged; Institute for Translational Medicine, University of Pécs and Professor Miklós Sahin-Tóth at the Department of Molecular and Cell Biology, Boston University Medical Center for all of their guidance, patience, inspiration and support during my time as a $\mathrm{PhD}$ student. Without their outstanding supervision, help and encouragement this work and this $\mathrm{PhD}$ thesis would not have been possible. I would like to express my thanks for thrusting me and giving me the possibility to have an international experience in the United States. They both are real inspiring experts and I really appreciate their knowledge.

I gratefully acknowledges the support and personal help of Dr. Csaba Bereczki (Department of Pediatrics, University of Szeged, Szeged, Hungary) who let me interrupt my clinical work and made me possible to working on these project in Boston. This work would not have been possible to accomplish without the help and support of Dr. Andrea Párniczky, Dr. Eszter Hegyi and Dr. András Szabó. I would like to express my sincere gratitude for all of their advices, knowledge and patience for designing and performing the experiments. I am grateful to Dr. Andrea Geisz, Dr. Balázs Németh, Dr. Dóra Mosztbacher, Dr. Fanni Zsoldos, Dr. Ákos Szűcs, Dr. Áron Vince, Dr. Ferenc Izbéki, Dr. Dorottya Berki, Dr. Alexandra Demcsák, Dr. Anita Balázs, Andrea Szentesi, all the members of the Hungarian Pancreatic Study Group and all the contributors to the Registry for Pancreatic Patients for their help and contribution to this work.

I would like to express my deep and sincere gratitude for Professor Ferenc Bari and Dr. Erzsébet Forczek for their support and guidance during the medical university, their opinion was realy important for me.

I am grateful to Dr. Endre Neparáczki for helping me editing this $\mathrm{PhD}$ thesis. Finally i would like to say special thanks to my Parents and Grandparents for their unconditional help and support in my life. 


\section{Financial support}

This work was supported by NIH grants R01DK095753, R01DK082412 and R01DK058088 (to MST) and the Momentum Grant of the Hungarian Academy of Sciences LP2014-10/2014. 